Article

\title{
What Is a Videogame Movie?
}

\section{Mike Sell}

Citation: Sell, Mike. 2021. What Is a Videogame Movie? Arts 10: 24. https://doi.org/10.3390/arts10020024

Academic Editor: Christian Thomas

Received: 1 December 2020

Accepted: 25 March 2021

Published: 12 April 2021

Publisher's Note: MDPI stays neutral with regard to jurisdictional claims in published maps and institutional affiliations.

Copyright: (C) 2021 by the author. Licensee MDPI, Basel, Switzerland. This article is an open access article distributed under the terms and conditions of the Creative Commons Attribution (CC BY) license (https:// creativecommons.org/licenses/by/ $4.0 /)$.
Department of English/Graduate Program in Literature \& Criticism, Indiana University of Pennsylvania, Indiana, PA 15705, USA; msell@iup.edu

\begin{abstract}
Cinematic adaptations of videogames are an increasingly common feature of film culture, and the adaptive relationship between these mediums is an increasingly common subject of film and videogame studies. However, our ability to historicize and theorize that relationship is hampered by a failure to fully define the generic character of our object of study. This essay asks, what is a videogame movie? It argues that film scholars (1) have not considered the full range of ways videogames have been represented in film; (2) have not attended fully to the historical, technological, figurative, and social dimensions of videogames; and therefore (3) have limited the set of possible texts that comprise the genre "videogame cinema." The essay recommends a tropological approach to the problem, defining six tropes that comprise the "videogame movie" as a genre, and applying them to two films, Her and 1917, neither of them a direct adaptation of a videogame, the latter not "about" or referencing videogames in any way, yet both exemplary of a broadened concept of "videogame cinema".
\end{abstract}

Keywords: videogames; film; adaptation; genre; tropes; methodology

\section{Introduction}

The relationship between film and videogames is usefully understood as "problematic", in the best sense of the term. Both mediums are shaped by intersecting historical, technological, social, cultural, economic, and performative factors-as is the relationship between them. The sorts of videogames that we play now are different than those we played two decades ago, as are the movies we watch. The kinds of movies we watch about videogames now are different than those we watched two decades ago. The ways videogames adapt cinematic techniques and stories are different, too. Those who watch movies and play games experience the relationship between them differently now than in the past. When I was a child, we watched movies in theaters and played games in arcades and on home consoles and PCs. Now, I often play and watch on the same devices, occasionally at the same time. And what about that "we" who plays, watches, and makes those movies and games? That "we" is as contingent and diverse as the mediums "we" love.

The complexity of the adaptive relationship between videogames and film has been recognized by scholars for some time, including the contributors to Geoff King and Tanya Krzywinska's ScreenPlay: Cinema/Videogames/Interfaces (King and Krzywinska 2002) and Gretchen Papazian and Joseph Michael Sommers's Game On, Hollywood!: Essays on the Intersection of Video Games and Cinema (Papazian and Sommers 2013), by Ryan in her monographs and edited and co-edited collections on cross-media adaptations and storyworlds (for example, Ryan 2004; Ryan and Thon 2014), and by Jasmina Kallay's monograph Gaming Film: How Games are Reshaping Contemporary Cinema (Kallay 2013). These have established paradigmatic topics for the field: the differential nature of interactivity between the mediums, the productive tension between adaptation and remediation, the growing role of global corporations in the production and propagation of the adaptive relationship (most notably, via the emergence of what Henry Jenkins calls "transmedia storytelling" (Jenkins 2006)), the proliferation of fan communities as critics and creators (i.e., "participatory culture"), the persistence of negative stereotypes and damaging tropes, and the 
distinct ways that videogames and films construct narratives and storyworlds. In diverse ways, these scholars have provided theoretical and historical context for what Antoni Roig et al. characterize as "a new relationship between subject and representation that goes far beyond the 'spectatorship' position, pointing to a playful relationship with images that may be useful to understand new forms of media practices" (Roig et al. 2009, p. 89).

However, each of these inquiries falls short in one specific way: a failure to properly define their scholarly object, the videogame movie. I presume they share with me the desire for a theory of cinematic videogame adaptation that can endure the historical, technological, social, cultural, economic, and performative transformations that continue to shape both mediums, a theory that is applicable to the full range of texts that comprise the film/videogame adaptive relationship. But exactly how wide is that range? What are the texts that comprise the category? In the absence of an accurate and encompassing definition of the videogame movie, our analyses will be inevitably partial, both in the sense of being incomplete and in the sense that they express a preference towards a specific, but limited set of cinematic texts.

What is a "videogame movie"?

It is fairly obvious that Super Mario Bros (1993), Silent Hill (2006), and Sonic the Hedgehog (2020) are adaptations of videogames, thus are videogame movies. Jumanji: Welcome to the Jungle (2017) and Wreck-It Ralph (2012), while not based on real-life intellectual properties, are self-evidently adaptations (more accurately, pastiches) of videogame genres, telling their stories with an immediately recognizable focus on the tropes and mechanics of the kinds of games they adapt. They are videogame movies.

War Games (1983) is another obvious addition to our list. John Badham's film remediates and narrates the computerized wargames developed to model the complex geopolitical strategies developed during the Cold War between the U.S. and the U.S.S.R. The film's primary adaptation is complicated by other adaptated elements: the Galaga game that opens the film and the digital version of Tic Tac Toe that David plays with the artificial intelligence Joshua in order to teach it about the futility of war. War Games is in essence three different kinds of videogame cinema in one movie. Each of the games is adapted differently in the film-each looks and sounds different, each impacts the narrative differently. Regardless, it is on the list.

What these films share in common is a feature noticed by Johnson (2019) in his essay, "Deep Play and Dark Play in Contemporary Cinema". These are texts "with games at their center: the characters might be playing a game or be acting within a game or structuring their activity as if it was a game, or some equivalent" (p. 406). Further, "the game is the film: these are films entirely concerned with the play of the games they depict, and when other elements of a fictional universe are shown on screen, those are secondary or incidental to the play of these games or help to explain to the viewer the nature of the game being played" (p. 406). That is certainly true of the films considered in ScreenPlay, Game On, Hollywood!, and Gaming Film. These movies center their attention on videogames, whether specific intellectual properties or recognizable genres. Many of them are adaptations. Some use games figuratively as a vehicle for broader social commentary, whether those concern marginalized identity and self-acceptance (as with Wreck-It Ralph) or the disruptive effects of emergent technologies on family relationships (as with Tron: Legacy [2010]).

But let us consider some less obvious possibilities. Would we include on the list of "videogame movies" 2001: A Space Odyssey (1968), which features a brief scene in which Frank plays digital chess with the artificial intelligence Hal? Would the holographic game of Dejarik played by Chewbacca and C-3PO justify adding Star Wars: A New Hope (1977) (see Figure 1). Would the bit in John Carpenter's 1982 The Thing where MacReady pours scotch over a (fictional) Chess Wizard machine and the brief cameo of Asteroids Deluxe earn that film a spot on our list (see Figure 2)? I would argue that all of these are at least worth a consideration as examples of videogame adaptations, though the significance of the videogames in each of these films is distinct, as are the adaptive strategies used by their respective filmmakers. These films illustrate King and Krzywinska's argument 
that the adaptive relationship between films and games encompasses not only narrative, but also audio and visual tropes, shared iconographies or mise-en-scène, point of view, and so on. While the videogames that appear in these movies may well carry figurative significance (most obviously, the chess game in 2001 as a synecdoche of Hal's ruthless logic), they also represent particular modes of what Andrew MacTavish describes as "visual and auditory technology display" and particular modes of gameplay whose effects in the text may function independently of any specific narrative or figurative significance (MacTavish 2002, p. 34). Indeed, since they are not the center of attention, the videogames in 2001, Star Wars, and The Thing may provide "clearer insight into the way gaming affects our daily activities, including the lives of those who do not play games or participate in new media practices" (Boellstorf qtd. in Roig et al. 2009). This idea can be applied both to characters in the film (i.e., C-3PO and Chewbacca as players of videogames) or to the audiences who watch them, who may have no particular expectation that a videogame would appear in the movie they've chosen and likely have diverse responses to it. (I, for one, had not given the videogames in these films a second thought until I began writing this essay.) In the same way that a "more inclusive theory of computer gameplay" can open consideration of a wider range of cinematic adaptation strategies in videogames and a wider range of gameplay pleasures (MacTavish 2002, pp. 34,35) a more inclusive theory of cinematic representation can alert us to a wider range of videogame adaptation strategies in films.

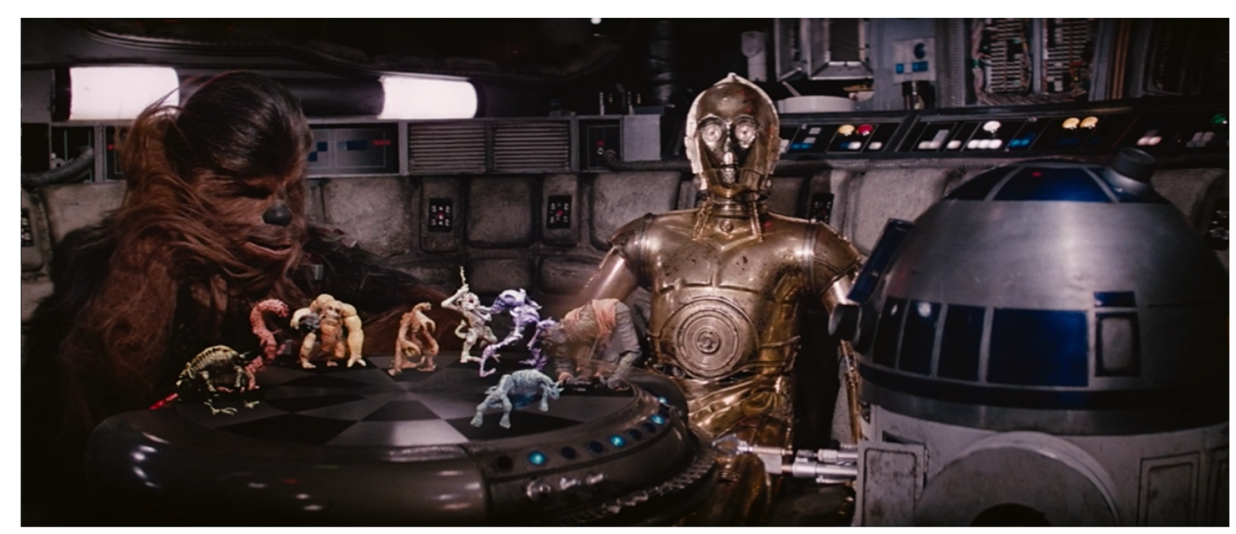

Figure 1. Chewbacca plays R2-D2 in a game of Dejarik (a.k.a. Holochess) while C-3PO observes in this scene from Star Wars: A New Hope (1977). (Screenshot created by author).

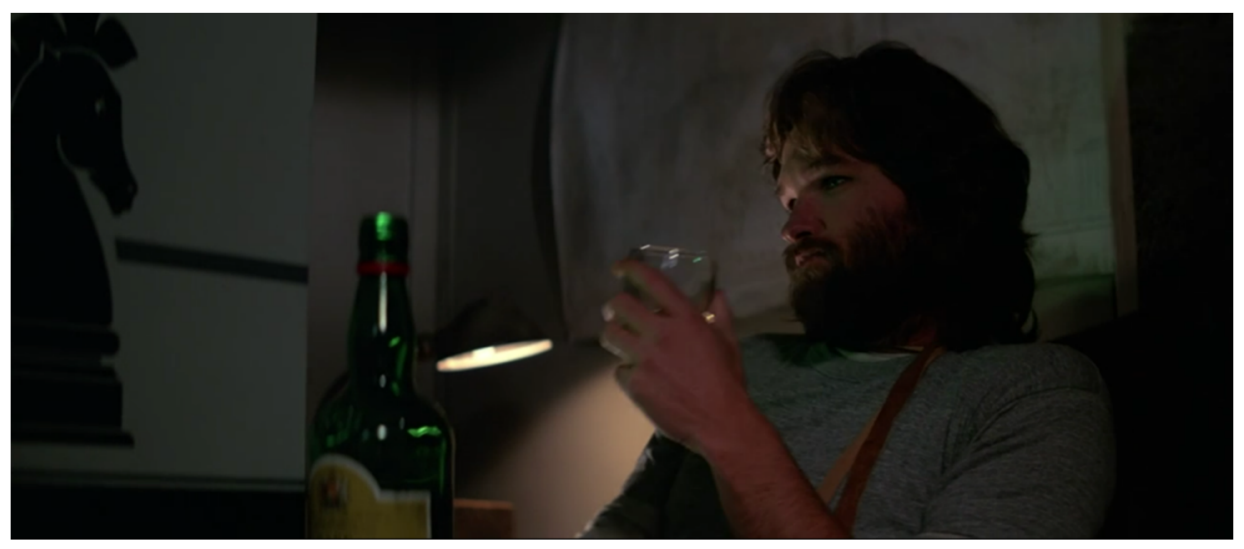

Figure 2. MacReady plays Chess Wizard in The Thing (1982). (Screenshot created by author).

We might take this inquiry in a more speculative direction by querying the very notion of a videogame. Before we can answer the question, What is a videogame movie?, we need to answer the question, What is a videogame? This is a surprisingly difficult question to answer. Those who've asked it have alerted us to assumptions about the 
technology that comprises the videogame as medium (Karhulahti 2015; Sicart 2017); to the diverse histories and play cultures of and around videogames, many of them yet to be brought into the fold of scholarship (Boluk and LeMieux 2017; Penix-Tadsen 2016) to the hazards of focusing only on big-budget games produced by multinational corporations (Anthropy 2012); and to the heteronormative, nationalist, and ethnocentric ideologies that shape not just what videogames are made, but the play cultures and game literacies that are affirmed or marginalized by those ideologies (Clark and Kopas 2015; Shaw 2014). How do assumptions about what a videogame is shape our understanding of videogame cinema and, thus, the texts we might consider as objects of study? In a 2002 essay, Steve Keane suggests that speculative-fiction films like Brett Leonard's The Lawnmower Man (1992), James Cameron's Strange Days (1995), and David Cronenberg's eXistenZ (1999) explore the "developmental gap" between cinematic possibility and "the technical limitations of current videogames and videogame systems" (Keane 2002, p. 149). Hearkening back to the classic function of speculative fiction, films like these can drive the conceptualization of interactivity, play, and the human/machine interface. However, while I agree that it is important to look to the imagined future to find visions of videogames that are not constrained within current technoculture, I suggest that we look to the past as well.

As a provocation, let us consider the 1950's U.S. children's television show Winky Dink and You. What set this otherwise anodyne network-television product apart from its competitors was its technological supplement. Viewers could mail-order a thin electrostatic sheet of plastic, called a "magic window", attach it to their television screen, and draw on it with special "magic crayons". In each episode, the viewer would be asked to complete connect-the-dots puzzles that enhanced the narrative (for example, drawing a cage around a lion or a bridge over a chasm), revealed hidden messages, or created a character for the actors to converse with. Winky Dink and You involved a non-trivial interaction between its audience and an electronic screen, an interaction that visually altered the appearance of the image and the narrative. Further, the screen and crayons could be used for more mischievous ends; for example, drawing a mustache on the President during a State of the Union address, a low-tech form of "glitch play". In other words, it has much in common with what we would call a videogame.

Though I have found no evidence that children's author Crockett Johnson was influenced by Winky Dink and You (or vice versa) when he created his popular Harold and the Purple Crayon series, the story of a little boy altering his reality with a magical drawing implement is curiously similar to what the producers of Winky Dink envisioned and implemented. Both texts reflect a shared interest in the idea that a child, liberated from the constraints of everyday responsibilities, could use a handheld device and a screen to achieve narrative agency and shape the storytelling world in non-trivial ways. Further, both texts deploy their interactive technologies to construct overlapping "narrative framings", in Wolf's sense (Wolf 2006), enabling the child with their writing instrument (one in real-life, the other in a make-believe story) to generate a self-authored paratext to reinforce the frame of the primary text (connecting the dots as directed by Winky Dink) or modify it to their own tastes. The Purple Crayon series and Winky Dink and You might be considered adaptations of a shared speculative imaginary, a shared vision of what a videogame might be in advance of what videogames actually became.

A similar example is Daniel F. Galouye's 1964 novel Simulacron-3, a psychedelic sci-fi story about a scientist involved in a corporate virtual-reality simulation designed to track public opinion, industrial, and political trends, but that (of course) is revealed as something far more sinister-and epistemologically dizzying. As with Winky Dink and You, we find in Galouye's text what might be considered a "speculative videogame," one that resembles simulation games released decades later like the Sim City (1989-present), The Sims (2000present), and Civilization (1991-present) series. If we are willing to consider Galouye's novel a videogame novel, then Werner Fassbinder's two-part television film World on a Wire, an adaptation of Galouye's novel, might be considered a "videogame movie", a cinematic adaptation of a novel about a speculative videogame. Were there space, I might develop 
this line of investigation and explore how those two texts precociously represented-and arguably shaped future representations of - the interface between the human body and computer hardware, digital nativity, the Anthropocene, and the tension between narrated subjects and programmable objects, to recall Seb Franklin's distinction (Franklin 2015). Rather than exploring the "developmental gap" between cinematic possibility and "the technical limitations of current videogames and videogame systems" (to recall Keane again), Galouye and Fassbinder explore the "imagination gap" between present reality and possible future. Identifying prototypical, atypical, or speculative texts like these can shed new light on the questions we have asked not only about virtual reality, but about videogame cinema itself. Given their shared themes, we might take a different look at Total Recall (1990), Arcade (1993), Nirvana (1996), The Matrix (1999), The Thirteenth Floor (1999, a remake of World on a Wire), and Avalon (2001). None of these would fulfill Johnson's criteria of what makes a movie a "game movie," since they do not have "games at their centre" (Johnson 2019, p. 406). However, they all concern forms of play within digitally generated environments and the conceptual intersections between ludic competition and other social concerns (Johnson 2019, p. 407).

\section{The Six Tropes of Videogame Cinema}

Ultimately, the questions I am exploring here are questions of genre, of what makes "videogame movies" distinct from other kinds of movies. And, as I hope to have demonstrated, the designation of a text as a videogame movie has tended to be determined by how we designate the videogame as such and the quantity and quality of the videogame's presence in a given text. In this essay, I will describe a more capacious, though more precisely defined framework for designating "videogame movies." I will define six tropes that identify a work as a videogame adaptation. I will then apply these tropes to two films, Her (2013, dir. Spike Jonze) and 1917 (2019, dir. Sam Mendes), two films that do not have games at their center, but that offer pertinent insights regarding videogames, videogame players and designers, and videogame culture when the specific position of videogames within them are properly recognized. 1917 is an especially interesting text, as it is a film that is not "about" videogames, videogame players and designers, or videogame culture in any way, but represents an evolution in the cinematic experience driven by the emergence into the broader public sensorium of a new way of seeing and feeling film narrative. I hope to refine a set of analytic tools that enables scholars of the videogame/cinema adaptive relationship to identify their proper textual objects and open that inquiry to a broader range of questions. In a more tentative vein, I would hope that, by defining the genre of videogame cinema in tropological terms, I will help to energize the search for examples beyond the obvious, as I suggested above with Winky Dink and You and World on a Wire and do here with Her and 1917. Finally, I would hope to open our eyes to different possibilities, different futures to videogames, videogame play, and videogame culture-and perhaps different pasts as well.

The six tropes of videogame movies are as follows:

Fictive adaptation: Movies, television shows, web series, machinima, etc., whose narratives are envisioned within the fictional parameters of a specific videogame or videogame genre. The Resident Evil films (2002-2021) and World of Warcraft (2016) come to mind, in addition to those I have mentioned above such as Super Mario Bros, Silent Hill, and Sonic the Hedgehog. I would also include in this category movies that tell stories within the fictional parameters of recognizable game genres. The protagonists of the web series The Guild (2007-2013) represent players of The Game, a thinly-veiled parody of World of Warcraft.

Supplementary adaptation: These include corporate-produced films intended to "fill in" or "expand" the storyworld of a videogame in canonical fashion; for example, the short, animated films one can find on the official Overwatch website, which provide backstory to the various characters. These would also include fan-produced artifacts that fulfill a similar function either in terms of the individual creator (what is called "head canon") or a 
wider, shared fan culture ("fanon"), such as Burnie Burns's Red vs. Blue machinima series (2003-2020), which takes place in the Halo universe.

Diegetic representation: Videogames, players, designers, game play, and game culture that appear in a film and serve a narrative function. These would include the imaginary chess videogame in 2001: A Space Odyssey, the actually existing Asteroids Deluxe game in The Thing, the imaginary videogame players in The Guild, and the actually existing designers in the documentary movie Thank You for Playing (2015). They might serve a central role in the narrative, as does the game and player in The Last Starfighter (1984). In that film, Alex Rogan's expertise with the fictional arcade game Starfighter brings him to the attention of an intergalactic military recruiter. Or they might play a relatively incidental role; for example, the Pong game played between a behavioral scientist and a chimpanzee in The Parallax View (1974) or the scene in Swingers (1996) when the characters play NHL '94.

Intertextual reference: These are sometimes referred to as "Easter eggs" and include elements of actually existing videogames, videogame phrases, sounds, shapes, images, movement patterns, environmental design, and so on briefly, often cryptically referenced in a film. These can be quite specific (i.e., the brief passage of music from The Legend of Zelda: A Link to the Past in Scott Pilgrim vs. The World (2010)) or more general (Hudson yelling, "Game over, man! Game over!" in Aliens (1986)). Unlike diegetic representations, intertextual references will likely be noticed only by those with knowledge of the original source text. They appeal to a specific audience.

Figurative representation: Videogames, players, designers, game play, and game culture that serve as symbol, metaphor, metonym, analogy, allegory, etc. For example, the Galaga game David plays in War Games synecdochically establishes him as an expert videogame player. Similarly, the fact that Nadia in Russian Doll (2019) is a game designer cues us to the fact that she approaches her life as a problem to be solved rather than an experience to be lived and loved.

Procedural adaptation: This is perhaps the most challenging trope to detect because it exists on a more fundamental, structural level than the other five; for example, mise-enscène, narrative structure, or character development. For this reason, I will discuss it in more detail when I discuss its application in Her. Broadly speaking, procedural adaptation involves a game mechanic or procedure; for example, leveling, respawning, manipulating an avatar, first-person perspective, or glitch play. We might think of the "respawn" or "time loop" mechanic that allows a videogame player to continue their game after the death of their avatar. We see this mechanic in many films, none of which are centered on games, in Johnson's sense (Johnson 2019): Groundhog Day (1993), Run Lola Run (1998), Los Cronocrimes (Timecrimes 2007), Triangle 2009), Source Code (2011), Live Die Repeat: Edge of Tomorrow (2014), Respawn (2015), Happy Death Day (2017), The Endless (2017), Russian Doll (2019), El Increible Finde Menguante (The Incredible Shrinking Weekend 2019), and Palm Springs (2020). Some draw attention to themselves as procedural adaptations: characters in Respawn and Russian Doll, for example, comment on the fact that they are experiencing something that resembles a videogame. The others do not. One of the unique characteristics of procedural adaptation is that it can be identified in texts that do not otherwise represent videogames, game players, or game culture, such as Groundhog Day, Sliding Doors (the branching narrative), or 1917 (the third-person shooter). Procedural representation, I would argue, is an index of the increasing ubiquity of play in media, a trend noted by, among others, Henry Jenkins (2006) and Matt Hills (2002).

An element of videogames, videogame players or designers, and videogame culture can play multiple tropological roles in a single text. The fifth episode of the first season of the AMC television series Halt and Catch Fire (2014), for example, adapts the interactive fiction Adventure (1977) in several ways. It does so diegetically: we see characters playing and hear them talking about it. The game helps establish and build character: Yo-Yo is shown to be a deeply knowledgeable player: he realizes Cameron is playing by the sound of her keystrokes. The game moves the plot forward: the coders who complete the game - by wit or by cheating — are identified by Cameron as creative problem-solvers 
whom she recruits for a special project that will become the focus of the series' next season. Adventure functions metonymically, too. Along with the costumes, props, and set, it helps establish the early-1980s setting of the episode. It functions as a metaphor for the characters' desire for a life that is bigger, riskier, and more rewarding. Indeed, the title of the episode is "Adventure".

The tropes I have described are not a foolproof measure for determining whether a particular film can be designated as a "videogame movie." I am of two minds about Groundhog Day, for example, as its use of the respawn mechanic feels different than, say, Edge of Tomorrow, the first season of Westworld (2016), or Russian Doll. Further, I am not convinced that considering it as a "videogame movie" provides any particularly useful critical insight. But the six tropes I have defined here are reliably useful for the purposes of, first, identifying and, second, analyzing texts. The same can be said of Sliding Doors and the branching narrative procedure. The notion that diverging roads might lead to quite different ends is an antique notion. And while the tropes provide a more refined set of tools to discuss game-centered films, they are also useful when applied to films that are not. Indeed, it is likely that we will learn more about the cultural significance of videogames and the nuances of the videogame/film adaptive relationship by examining instances that do not draw attention to themselves, that appear "incidental." That is the task to which I will turn presently with the films Her and 1917, focusing in particular on procedural adaptation, as I think it is the most interesting trope both formally and historically. Ultimately, I intend the analyses of these two films to demonstrate the utility of the six tropes in terms of elucidating and articulating formal characteristics and building a critical framework that generates pertinent insights into both the film's formal and narrative characteristics and their position within the ongoing history of the videogame/film adaptive relationship.

\section{Her: The Quest and the Avatar}

Spike Jonze's 2013 Her is not a movie about videogames. Her is about loneliness. Her is about the loneliness we can feel with the people we have loved the most and the longest. It is about the loneliness that happens when we realize how selfish we have been. Yes, it is a tad twee and distressingly White. But I respect Jonze's earnest effort to explore the way it feels to be alone among the ones we love or want to love. Her is an intriguing example of videogame cinema precisely because videogames are not the focus. But a closer look at how videogames, videogame players and designers, and videogame culture are deployed by Jonze and his team can help us gain some critical traction on the movie's themes, its characters, the world they live in, and the story that Jonze wants to tell about love and loneliness in a world of algorithmic intimacy.

Her takes place in a near-future where artificial intelligence is affordable and ennui is as common as high-waisted pants. Our protagonist, Theodore Twombly (Joaquin Phoenix), is a mustached, normcore thirty-something who works for a company that ghostwrites personal letters for its clients. Though he is an expressive, empathetic, talented writer, Theodore, like his clients, struggles to express his feelings. A divorce has left him bruised and desperate for someone to love and to love him. On a whim, he purchases an operating system for his computer that includes an intuitive, intelligent virtual assistant designed to evolve in relationship to its user. In the words of its sales pitch, "It's not just an operating system. It's a consciousness." Long story short, Theodore falls in love with the AI, who names herself "Samantha", played with breathy ebullience by Scarlett Johansson.

So, what are videogames doing in Her?

First, there is diegetic representation. Videogames are part of the story. We see Theodore playing them. He plays a first-person game set in an underground labyrinth. (Though unnamed, it is conventionally referred to as "Alien Child" after the foul-mouthed NPC that appears in it). He plays another called "Perfect Mom," in which the player attempts to meet the challenges of being, you guessed it, a perfect mom. We hear him casually chat with a date about playing videogames. Theodore's friend Amy (Amy Adams) is a videogame designer-in fact, she is the designer of "Perfect Mom." And there is a third 
videogame Theodore plays, one that may not be quite as obvious as the first two and which we might call the Samantha game. More on that in my discussion of the film's procedural adaptation of the quest mechanic.

There is a lot to like about the diegetic representation of videogames in Her. This is a world where videogames are a simple fact of life, where we might talk to a friend about a game as casually as we would an episode of television or a movie. I like that Jonze makes one of the characters a videogame designer and makes that designer a woman. This is not to say that the representation of videogames in Her is entirely unproblematic. In light of the persistent misogyny of videogame culture, I find both the Alien Child's trash-talking and Samantha's bemused response to it more than a little tone deaf. But by and large, I find the diegetic representation of videogames thoughtful and optimistic. Indeed, that representation situates $\mathrm{Her}$ as both a representation and example of the shifting relationships between audiences and emergent media and cross-media "logics" that produce new forms of spectatorial play. Following Roger Silverstone's argument, we might approach Her as both a diegetic representation of "the many ways in which we can see media as being sites for play, both in their texts and in the responses that those texts engender" (Silverstone 1999, pp. 59-60), as well as a text that requires a certain kind of playful cognitive activity from the audience typical of speculative fictions. I will return to this issue in my discussion of the avatar and procedural representation.

The second way videogames are used in Her is via figurative representation. They are metaphors. The first time we see Theodore playing "Alien Child," his avatar is strugglingand failing - to escape a labyrinth. Theodore is struggling too, trying and failing to find his way out of his emotional funk. In that real-life (but no less algorithmically computed) game, Samantha replaces Alien Child, serving as a guide and verbally enticing interlocutor to the emotionally paralytic Theodore. They reverse these roles after they have (verbal) sex for the first time. Theodore now helps Samantha find a way out of her own maze. "You helped me discover my ability to want", she tells him. Amy is trapped, too, trapped in other people's expectations. Not coincidentally, the game she is designing is in beta. "Perfect Mom" is not perfect; neither is Amy. And, as it turns out, it is another version of the AI operating system that helps Amy get out of her own emotional maze. And one of the ways she demonstrates her growing self-confidence is by glitching "Perfect Mom," demonstrating the arbitrary nature of its representation of femininity and motherhood.

The videogames in Her also serve as metonymic figures of futurity. The holographic and haptic interfaces of "Alien Child," the alacrity with which the NPC responds to the voices of Theodore and Samantha, and the sleek car with which "Perfect Mom" drives her kids to school help construct a world where technology is not just more advanced, but also more intimate, homely, and comforting. This is a classic example of how representations of videogames enable what Tom Boellstorf describes as "clearer insight into the way gaming affects our daily activities, including the lives of those who do not play games or participate in new media practices" (qtd. in Roig et al. 2009). As production designer K.K. Barrett explains,

This movie is really all about the human experience. It's all about someone falling in love through a window of technology, but the technology does not stand in the way. The technology is an enabler or a comfort. So, when we began thinking about the world of this film, it was about creating a comfortable surrounding. This was Spike's mandate: this was not a dystopian future. This wasn't necessarily a utopian future, but it was a world where everything you wanted was there for you, except for the solutions to the human dilemma of 'how do we get close to each other, how do we stay close to each other, how do we trust each other?' (Qtd. in Abrams 2013)

That tension between the promise of technology and the realities of the heart is key to the third way videogames are used by Jonze in Her - and to how the film demonstrates the effects of playable media on everyday life and subjectivity. 
This is procedural adaptation, which is when a videogame procedure, mechanic, or game feel is adapted to another storytelling medium. As a literary critic and historian, I find this dimension of videogame cinema the most intriguing. And given that $\mathrm{Her}$ is a movie about operating systems-that is, the invisible software that enables all the other programs to run on a computer-thinking about procedures in the film is all the more relevant and, as it turns out, revelatory.

"Procedural adaptation" is my literary-critical mod of Ian Bogost's concept of "procedural rhetoric". Videogames are systems. They represent the world and the things in it via systems-rules systems, algorithmic systems, feedback systems, and so on. Procedural rhetoric is the term Bogost invented to name how these systems communicate values. He explains,

[T]he gestures, experiences, and interactions a game's rules allow (and disallow) make up the game's significance. Videogames represent processes in the material world-war, urban planning, sports, and so forth—and create new possibility spaces for exploring those topics. That representation is composed of the rules themselves. We encounter the meaning of games by exploring their possibility spaces. And we explore their possibility spaces through play. (Bogost 2008, p. 121)

Bogost points to Animal Crossing (2001) as a good example of procedural rhetoric. On one hand, it is game about making friends, fishing, searching for shells and insects and discontinued designer furniture, and so on. But it is also a game about consumerism, debt leverage, and entrepreneurialism. In contrast to your adorably contented neighbors, the "the player participates in a full consumer regimen: he pays off debt, buys and sells goods" (Bogost 2008, p. 118). They borrow money from the entrepreneurial tanuki Tom Nook to expand their home, and Tom uses the interest from that loan to grow his store, whose expanded product line tempts the player to spend and borrow even more, and so on and so on. Ultimately, Animal Crossing "is a game about the bittersweet consequences of acquiring goods and keeping up with the Joneses," and it "accomplishes this feat ... by creating a model of commerce and debt in which the player can experience and discover such consequences. In its model, the game simplifies the real world in order to draw attention to relevant aspects of that world" (Bogost 2008, p. 119).

A vivid example of procedural adaptation can be found in the fourth episode of the first season of the HBO series Westworld. A gunfight has just ended, and one of the characters spies a pistol on the blood-spattered floor. "Ooh!" he exclaims, picking it up. "Upgrade! Nice!" He then discards his old gun in favor of the new. The videogame procedures adapted here are familiar: inventory management, acquiring better weaponry as one overcomes challenges, "leveling up", as it were. What does it accomplish in terms of storytelling? In this case, the fact that the procedure has been adapted is foregrounded. It functions both procedurally and intertextually, alerting the viewer that the super-futuristic Westworld resort is dependent on the tropes of antique videogames, that it is designed after a particular kind of game (roleplaying games), and that the character is an experienced gamer. It also communicates the values of that character-anything that happens in the park, including the emotional crisis his friend is suffering, is only a game. And the moment reinforces a major theme of the series: free will versus programming.

Procedural adaptation serves two functions in a film. First, it is a formal technique in which a procedure, mechanic, or game feel is remediated from one medium to another to enable various kinds of storytelling. Procedural representation enables playwrights, poets, and filmmakers to tell stories, create characters, and explore emotional experience. Second, procedural representation functions as a rhetorical technique. The embedded values of the given procedure, mechanic, or game feel are also remediated, though they are typically altered in the process. These two functions attain regardless of whether the text in question draws attention to the adapted procedure. The respawn mechanic functions as both a formal and rhetorical technique in Russian Doll (which self-consciously alerts us to 
its presence via its protagonist, identified in the first episode as a videogame designer) and The Edge of Tomorrow (where there is no diegetic reference to videogames).

Considered in the context of the increasing blurry line between games and other media, procedural representation can be considered not only an index of the videogame medium's generation of its own narrative, affective, and sensory techniques, but also the capacity of audiences to "become immersed in non-competitive and affective play" that enable "creative engagement and emotional attachment" that would not have been possible before the rise of videogames (Hills 2002, p. 112). In this sense, procedural adaptation reflects the dissemination from games to cinema of "understandings related to the practices, explicit rules (or procedures) of the practice, and motivations (objectives, emotions, goals, beliefs, moods, engagement) linked to the practice" of videogames (Roig et al. 2009, p. 93). However, procedural representation is not limited to texts centered on games or marketed to those who have experience with play. The case of 1917 portends a broadening of what Noah Wardrip-Fruin (2005) calls "playable media" (the incorporation in media of "textual instruments" designed to foster playful mindsets) and the increasingly difficult task of drawing a line between what is and is not a game. This tendency suggests a productive reversal of Lev Manovich (2001) reading of "transcoding": the reinterpretation of the "cultural layer" of representation through the "computer layer" of procedures (p. 46). Procedural representation suggests, in contrast, a reinterpretation of the "computer layer" through the "cultural layer," evident in both specific representational techniques and in the expectations and media literacies of audiences. Procedural representation is a vivid example of what Theodore Schatzki calls the "dispersed" and "integrative" practices of media culture. While the procedural adaptations I identify here originated in videogames, the understandings, rules, and motivations (to recall Roig et al. 2009, again [93]) of those procedure's original context have now become dispersed enough that creators can depend on them to "work" rather than depend on a specific subset of the audience to recognize them in terms of their relationship to that original context (i.e., videogame players recognizing a videogame procedure).

In practical terms, to analyze a specific instance of procedural adaptation, we need to identify what is being adapted. We need to identify how it is being adapted. We need to identify what the adapted element is doing in this new context both formally and ideologically. And we need to interpret the adapted element in context. Let's do that now.

What procedures, mechanics, or game feels are adapted in Her? I have already touched on one of them: The quest. The second is less obvious-it lacks the diegetic signals of the quest-but more central to the film's exploration of the tension between the promise of technology and the realities of the heart: the avatar. The quest and the avatar procedures are deployed so that they are significant to the film's dramatic arc but also pertinent to the film's perspective on the relationship of individuals to playable media and the playable mediation of interpersonal relationships.

Let's consider the quest first. In literature, a quest is a familiar plot device: a long, typically arduous search for someone or something. Jeff Howard defines it as "a goaloriented search for something of value" (Howard 2008, p. 14). The videogame version of the quest is similar: tasks given to the player-character that, when completed, earn them experience, wealth, recognition, and new challenges. However, one crucial difference between traditional literary and videogame quests is that the latter tend to be much more numerous (and tendentiously banal). There are more than 15,000 quests in World of Warcraft (2004-present), for example. This reflects a tension surrounding the quest procedure in videogames that has been described by Anne Sullivan, Michael Mateas, and Noah WardripFruin (Sullivan et al. 2009), a tension between tasks that are interesting and meaningful within the larger context of a game and that have a "noticeable (discernable) and significant (integrated) impact on the game world" and tasks that serve merely to advance a plot or lengthen the duration of play, often requiring a limited range of solutions (typically, combat, the gathering of items, or the discovery of new play areas). 
In Her, the quest procedure-and its tensions-is most obviously associated with Theodore. We see him playing "Alien Child", questing to escape the maze (see Figure 3). We see him playing "Perfect Mom", completing the innumerable "mini-quests" of a typical middle-class white mother's day (see Figure 4). The diegetic representation of games casts Theodore's character arc in what we might call a "procedural light," transforming it from the kind of conventional character arc typical of romantic comedies into a fairly trenchant critique of the imbrication of social technologies and social relationships. In that light, Theodore's desire for love resembles a quest, but a quest that is uninteresting, meaningless, and, ultimately, devoid of impact on his world. The problem is, Theodore is not a good gamer. When he plays "Alien Child", he needs help from both the child and Samantha to advance. When he plays "Perfect Mom", he gives the kids too much sugar and almost kills a crossing guard. However, with a little help from Amy, he generates jealousy points from the other moms in the game for bringing baked goods to school, becoming class mom in the process.

Which raises a question: Is Theodore bad at games or is he purposefully failing? Are the games he plays poorly designed or does he play them in such a way as to evacuate them of significance?

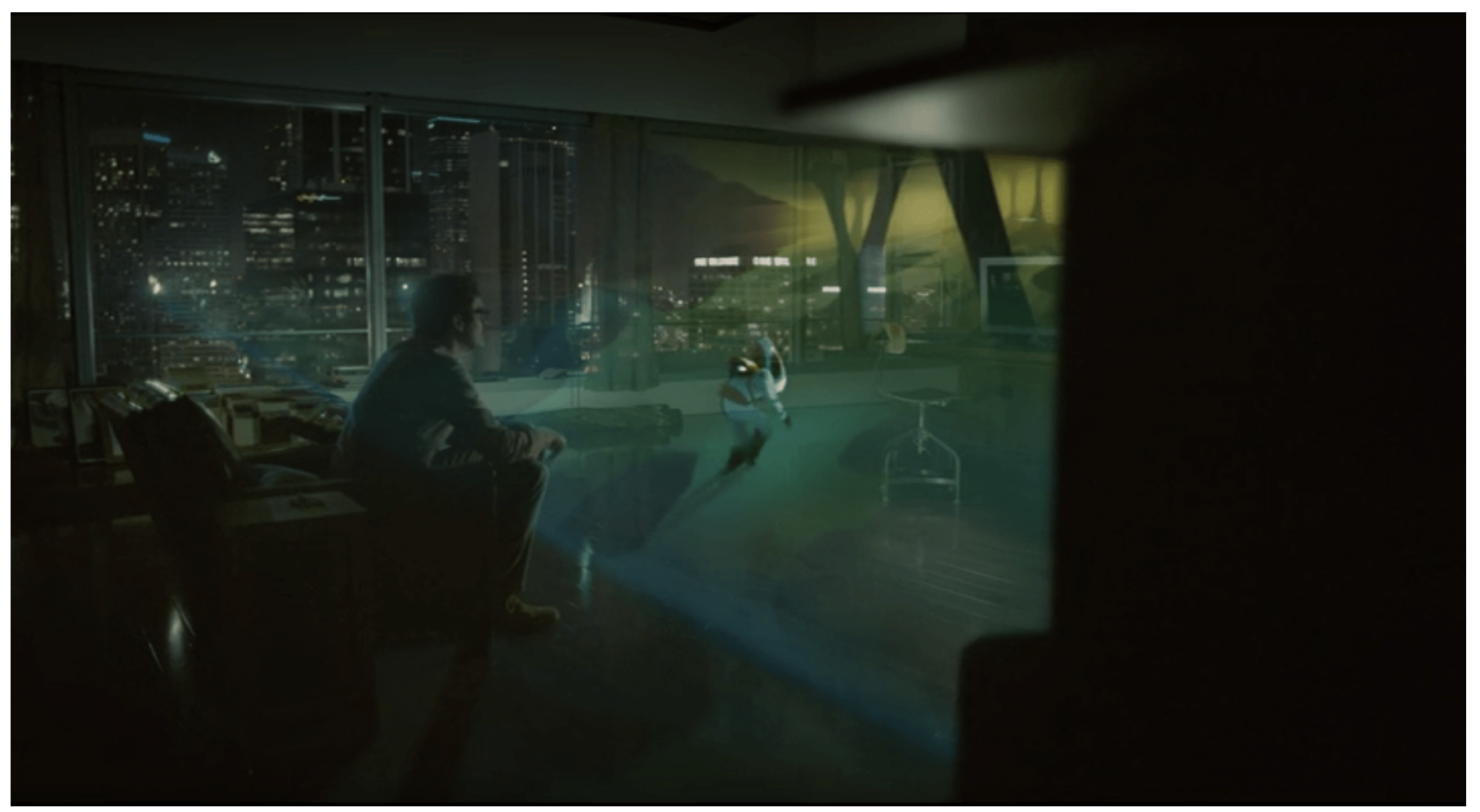

Figure 3. Theo plays Alien Child. (Screenshot created by author). 


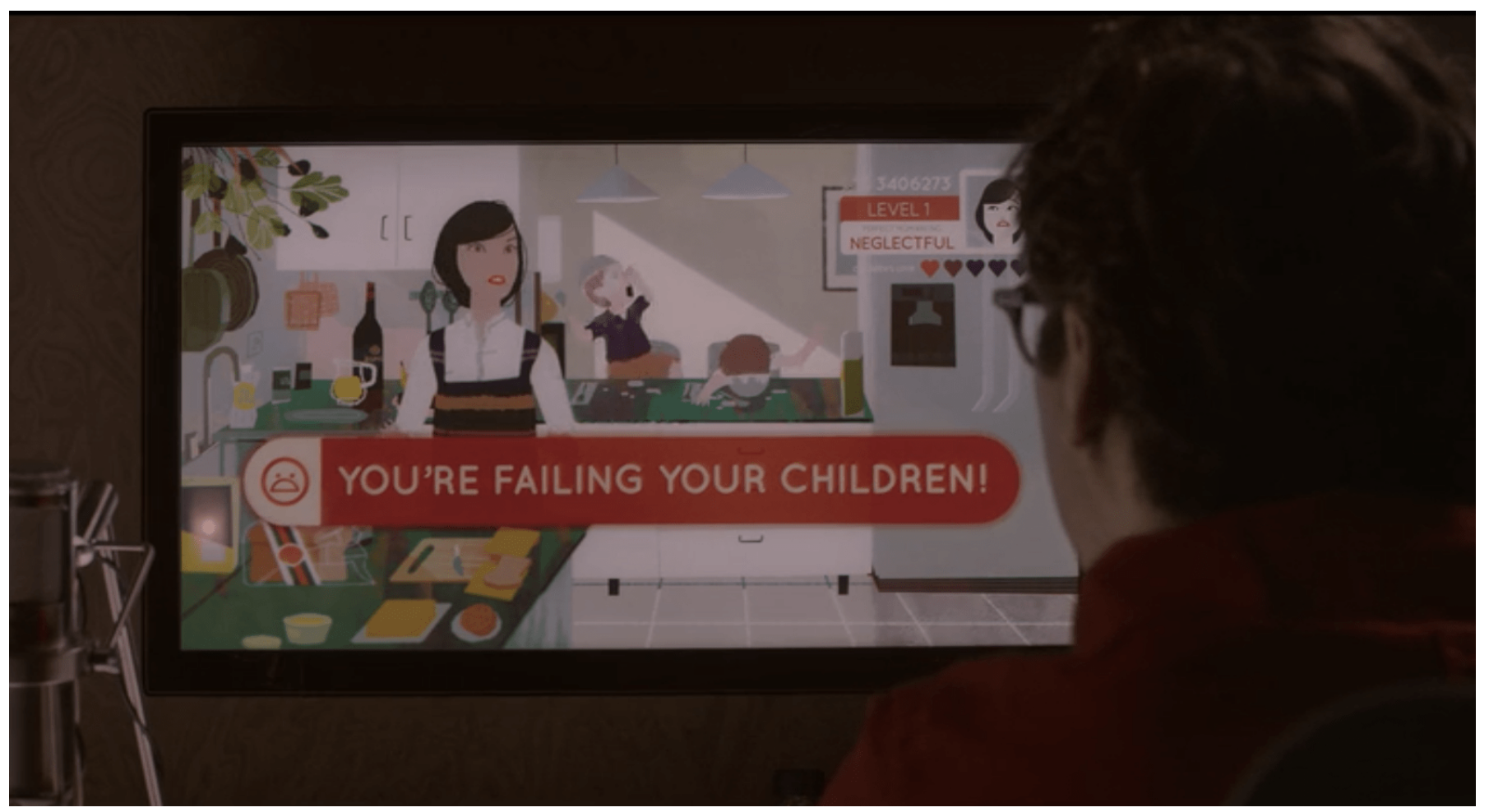

Figure 4. Theo plays Perfect Mom. (Screenshot created by author).

One way to answer that question is to consider his relationships to women. All of them, with the exception of Amy, are dysfunctional, if not catastrophic. When setting up the OS that will become Samantha, he complains that his mother only wants to talk about herself. But on several occasions, Samantha scolds Theodore for only wanting to talk about himself. His ex-wife Catherine criticizes him for refusing to deal with his emotions or acknowledging hers. "Am I really that scary?" She reminds him that he wanted to mold her into a fantasy image: "It's like you always wanted me to be this ... this light, happy, bouncy, 'everything's fine' LA wife, and that's just not me." At one point in the film, Theodore goes on a blind date. Despite the great chemistry and delicious kisses they enjoy together, he refuses to commit. She is understandably confused: "You know, at this age, I feel like I can't let you waste my time, you know? If you don't have the ability to be serious." When he equivocates, she burns the bridge: "You're a really creepy dude." And though Theodore helped Samantha realize what she wants from life, Samantha comes to the realization that he is incapable of understanding those desires, that he is limiting her potential, and that what he thinks she is, is not what she is-or what she can be. And she leaves.

It should come as no surprise that the person in the movie most associated with questing is the movie's most selfish character. After all, the quest trope often reflects a narcissistic vision of agency and heroism, typically associated with concepts of the "chosen one." This is often true of the quests we find in videogames. Why do not quest-givers simply gather their friends, fill a cooler with beer, and pick those twenty flowers from the Plains of Pacificity themselves? The answer, of course, is that those who grant quests exist mostly to affirm the hero's uniqueness and support their journey towards heroic apotheosis. Their incapacity is the index of the hero's agency; their anonymity the index of the hero's singularity. For this reason, the quest procedure can serve the lowest sorts of power fantasies, vulgar individualism, and egocentrism. This is certainly true of Theo, whose personal growth depends on the emotional exploitation of the women around him, most notably Samantha. 
The problem for Theo is that he has a limited understanding of what he wants and how he wants to get there. This is not entirely surprising. In a study of quest design in massively multiplayer online roleplaying games (MMORPGs), Anne Sullivan (2009) identifies two general failures. First, they fail to engage the full spectrum of problem-solving capacities, tending to focus on combat, rather than, say, environmental or interpersonal-relationship puzzles. Second, they tend to be "character neutral," meaning that whatever choices a player might have made in respect to their player-character's class, appearance, identity, and background do not significantly affect the choice, nature, or outcome of quests. The tendency to focus on combat or exploration is due to a number of factors, including the heavy "authorial burden" it places on developers to design diverse quests. But it is also due to gender bias and a tendency to limit quest design decisions to a small set of options that tend to be of interest to a minority of the videogame community. But even when the design is unimaginative, what players actually do while playing an MMORPG is more complex than constrained narrative framework of the quest. In his pioneering 2009 study of player demographics, motivations, and experiences, Nick Yee has shown that MMORPGs might "be thought of as a scenic chat room with a variety of interactive texts" (Yee 2006, p. 6). The draw of the MMORPG, in contrast to the single-player roleplaying game, is the opportunities for social interaction it affords. The rich social text-and the bonds it builds on and promotes-supplements the paucity of the quest text. And while "combat-oriented advancement" still tends to be the focus of most mainstream quest-oriented games, under pressure of the players who seek more diverse and personally meaningful play, "more diverse forms of advancement" are increasingly evident, particularly in the independent game scene (Yee 2006, p. 6).

Not coincidentally, the best questers in Her are the women. They know what they want and how to get it. They know how to pursue their goals without being trapped within Theo's limited understanding of personal development and agency. Catherine wants to grow emotionally and she refuses to provide Theodore a minute's more emotional labor. Theodore's unnamed date wants a committed relationship with a caring, passionate, fun person and knows she is not going to waste any more time with prevaricating egotists. Amy asks for a divorce from Charles, moves through it at speed (unlike Theodore, who repeatedly defers signing the papers), and discovers new sources of emotional health and creativity. Finally, Samantha responds to Theodore's emotional lassitude by developing independent interests and joining a circle of AIs who share her curiosity and affirm her desires. By the end of the film, the "non-player characters" that Theo depends on for his own growth have become "player-characters" in their own right, refusing to remain within the limited constraints of Theo's imagination.

Are the women's quests any less egocentric than Theodore's? No. But they do not harm others in the process, as is the case with Theo. In fact, their personal quests empower those around them to clarify and progress on their own quests, aligning with one of the strengths of the MMORPG: collaborating with other players to solve complex problems. Amy's ex-husband Charles joins a monastery and takes a vow of silence, seeking wisdom through introspection. The disastrous date catalyzes Theodore's first sexual encounter with Samantha. And Catherine and Samantha's respective exits force Theodore to reckon with who he is and how he treats others.

But Theodore's failure to complete his quest is not only a failure of courage and consciousness. Which leads to the second videogame procedure adapted by Jonze- the avatar-and one more woman harmed by Theodore's subpar gaming skills.

In videogame studies, an avatar is defined as the graphical and mechanical representation of the player. An avatar can be abstract or anthropomorphic, a cluster of pixels vaguely resembling a space ship or a photorealistic representation of a teenage octopus wandering a post-apocalyptic aquatic wasteland or a disembodied point of view, like the one we play in Gone Home (2013) or The Stanley Parable (2011). The avatar serves multiple functions in a videogame; as Katie Salen and Eric Zimmerman summarize, "as character in a simulated world, as a player in a game, and as a person in a larger social setting," and, on 
the other, "a tool, a puppet, [and] an object for the player to manipulate according to the rules of the game" (Salen and Zimmerman 2003, pp. 453, 454). But of course, the avatar can mean much, much more to those who play. We can become emotionally attached to our avatars. Though I do not play World of Warcraft anymore, I have fond memories of Daisypain, Thegodofn, Discodaddy, and Badmother. I feel a similar oneness with Mario, Lara Croft, Cloud Strife, Link, and Samus Aran. We have been through a lot together. Indeed, if you ask me about the adventures they had, I will tell you about the adventures I had. What is it about videogames that create that kind of emotional bond?

The scholarship on avatars is extensive, as it is widely recognized that the player/avatar relationship is central to the videogame medium and among its more complex affordances. Katherine Isbister characterizes avatars as one of the features of videogames that enable players to experience complex emotional responses to what they see, hear, and do-one of the "design innovations" of videogames that connect the experience of play to a game's fictional presentation (Isbister 2016, p. 2). She describes the avatar as both an "inhabitable protagonist" and a "prosthetic body" that unifies four ludic and fictive registers of play: the cognitive ("strategies, actions, and reactions [that] are rewarded over others"), the social (the "persona" of the avatar with its distinct "social qualities"), the visceral (the haptic, visual, and auditory qualities of its representation), and the fantastic (enabling the player to explore "alternative ... selves through actual in-game performance") (Isbister 2016, p. 11). Due to their shared technical and fictional qualities, avatars are an effective means for players to express identity, particularly in shared, online spaces, as Carina Assunção argues (Assunção 2016, p. 49). Indeed, the relationship between player and avatar can become quite intimate, a consequence of what Nick Yee and Jeremy Bailenson call the "Proteus Effect." Because the avatar "is the primary identity cue in online environments," a change in the appearance and mechanics of the avatar can significantly shape how the player understands themselves within that environment (Yee and Bailenson 2007, p. 274). In a sense, it is the very fact that we can treat the avatar like an object-a tool, a puppet, a thing to be manipulated-while also being cued to its qualities as character that enables us to experience it as a vehicle for identity exploration, self-expression, playful agency, and emotional experience.

But what if the avatar is not merely lines of code, pixels on a screen, and mechanics, but another human being? Treating a living being as a tool, puppet, or object is an entirely different matter than doing so with a virtual avatar. At first blush, this might seem a purely speculative concern. Yes, there are a small number of films that have explored this concept: Stay Alive (2006) is a horror movie where players of a videogame are killed in the precise fashion as their in-game avatars; the 2016 Black Mirror episode "Men Against Fire" describes a world where soldiers undergo neuro-cognitive modification so that they better achieve their mission objectives, essentially serving as ideological avatars of the company for which they work; and Gamer (2009) centers on the game Slayers, in which death-row prisoners fight each other while being physically controlled by others. Each of these films transposes the essentially technical question of identification and objectification into an ethical and moral framework. As it turns out, this is also true of Her, a film that explores the interpersonal and ethical dimensions of the player/avatar relationship by focusing on empathy.

Framing his analysis within the broader field of the performing arts, Gabriel Patrick Wei-Hao Chin agrees with Salen and Zimmerman that the bonds between player and avatar are due to a contradictory, mercurial experience of observation, manipulation, and identification, but he frames this experience in terms of empathy. Many videogames require only a kind of minimal, essentially technical level of empathy. For example, to empathize with Mario as he races around in Mario Kart requires us to do little more than share a common goal of winning a race. However, with more richly developed charactersrichly developed in terms of their technical and fictional qualities-empathy can be more complex. Chin argues that the quality of empathy that can be achieved in videogames is of a kind with theatre, dance, film, musical performance, and other art forms. Dee 
Reason and Matthew Reynolds call this common quality "kinaesthetic empathy," which they define as "a response constructed through the embodied process of engagement rather than through direct access to [the observed body's] feelings" (qtd. in Chin 2017, p. 207). In their 2012 anthology Kinaesthetic Empathy in Creative and Cultural Practices, they and their contributors demonstrate that the dynamic interaction of observers and observed, mediated by interactive environments that engage the mind, heart, and body, produces unique forms of engaged, empathetic witnessing (Reynolds and Reason 2012, p. 31). In $\mathrm{Her}$, the procedural adaptation of the avatar serves as the vehicle for the dramatic conflict between Theo and Samantha, a conflict that centers on the tension between empathy and objectification.

Unlike the quest procedural in Her, which centers on Theodore, the avatar procedural centers on Samantha. Samantha is an avatar, an artificial intelligence designed to provide its user day-to-day support, whether answering email, organizing files, reminding about appointments, or providing a sympathetic ear and a (virtual) shoulder to cry on. She is designed to be sensitive to subtle cues of voice and behavior, enabling her to adapt and evolve in response to the needs of her owner. Because Theo demonstrates the need for emotional support, Samantha provides that support, too, ultimately becoming a romantic partner for him. The rich subjectivity that the operating system is capable of achieving and expressing positions the operating system in an ambiguous space. While Theo's coworker hardly raises an eyebrow when he learns about his relationship with Samantha, his estranged wife finds it thoroughly offensive, another example of Theo's inability to deal with the reality of a woman's needs and expectations.

As it turns out, Samantha is also quite talented when it comes to operating her own avatars. The first is Theodore. Early in the movie, she orders him out of bed when he is moping about his divorce: “Up! Up, up, up, up! Come on, out! Out of bed!" And so he does. Shortly after, we see Theodore ambling through a carnival, arm extended, smartphone in hand, his eyes squeezed tightly shut. And guess who is controlling his movement? Samantha, of course, who tells him (by way of the phone's earpiece) when to walk, when to stop, when to turn, even when to sneeze (see Figure 5). The delight Theodore feels as Samantha guides him through the crowded carnival is evidence of her ability to understand exactly how Theodore's body works and, just as important, what he needs emotionally. Samantha is a natural kinesthetic empath.

But Samantha's strong capacity for kinesthetic empathy leads to frustration. One night, she wakes Theodore, anxious that they no longer have (verbal) sex. Theodore explains that this is a perfectly normal part of a relationship's evolution, but Samantha does not buy it. "I understand that I don't have a body", she offers. At first, we might assume that Samantha is worried about Theodore losing interest because of her lack of physical embodiment. But in fact, it is Samantha who wants more. She wants an avatar that is more than words, more than speech. "I found something that I thought could be fun", she tells him. "It's a service that provides a surrogate sexual partner for an OS-human relationship". In other words, it is a service that provides avatars.

The care and concern with which Samantha selects her avatar is further evidence of her skills as a kinesthetic empath and her understanding of the delicate balance between objectification and identification that she must achieve to make the game work (what Steve Dixon might characterize as the ability to dexterously negotiate the position of audience, participant, player, and character (Dixon 2007, p. 601)). The surrogate is, as she puts it, "a girl that I really like ... and I think you'd really like her, too." But while Samantha's relationship to the surrogate is empathetic (a question of liking and of knowing what Theodore would probably like), Theodore's is not. He assumes she is merely an object: "So, she's like a prostitute or something?" he asks. Samantha explains, "No, no, not at all. No. There's no money involved. She's just doing it because she wants to be a part of our relationship." He remains concerned: "I think someone's feelings are bound to get hurt". Samantha begins to lose her patience: "I think it would be good for us." And she tries her best to get Theodore to empathize with her. "I want this," she tells him. "Come on, this 
is really important to me". Cut to Theodore, sitting in his apartment, freshly showered, pounding a high-ABV beer.

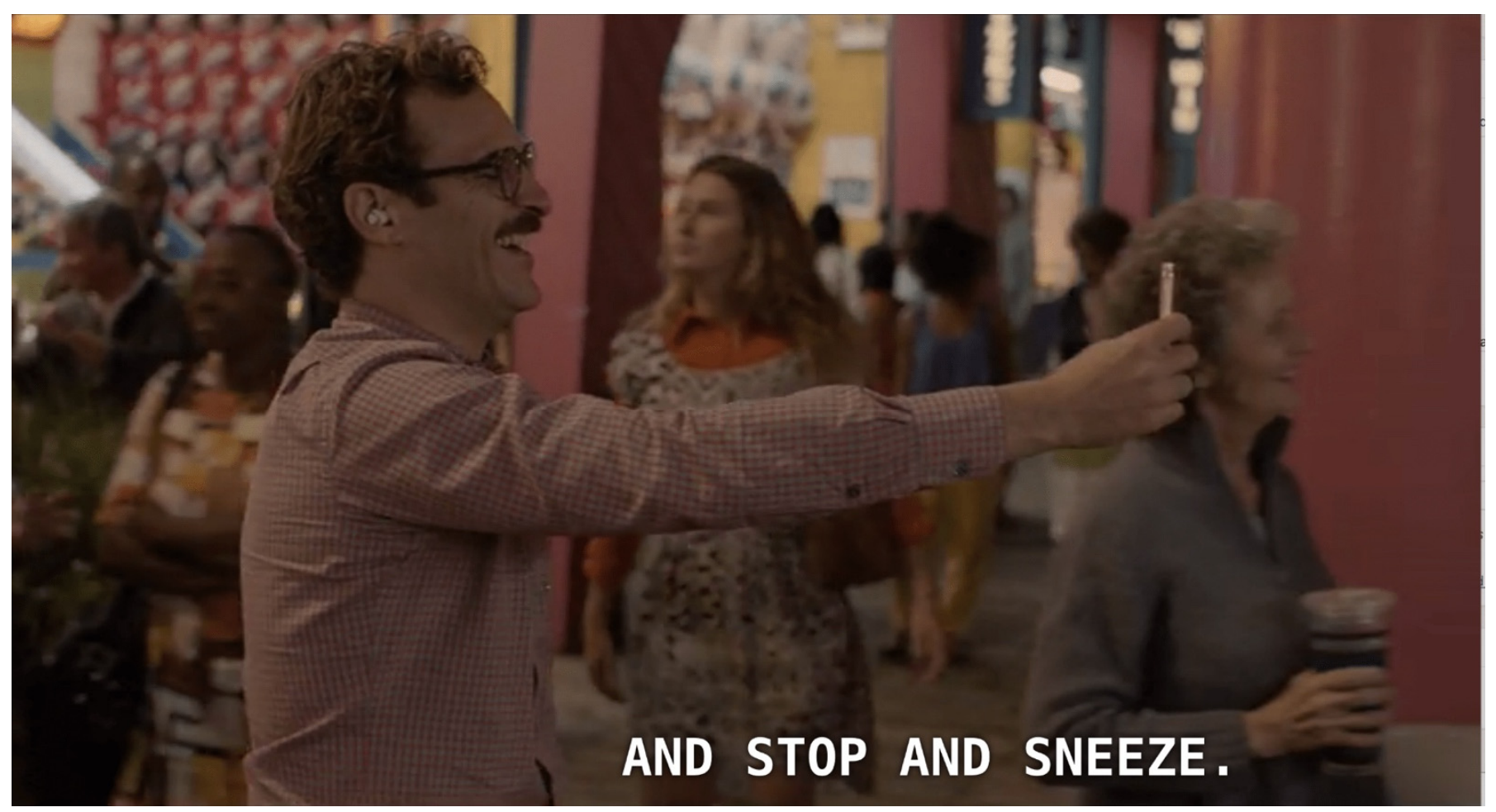

Figure 5. Samantha guides Theo through a carnival and tells him to sneeze. (Screenshot created by author).

Long story short, the evening is a catastrophe, but it is not Samantha's fault. The surrogate, Isabella, arrives, and Theodore gives her an earbud that allows Samantha to communicate with her without Theodore being able to hear and a small, freckle-sized camera to place next to her nose, so that Samantha can see from Isabella's point of view. Isabella is a classic example of a videogame avatar and an instantiation of Chin's theory of the way kinesthetic empathy is produced through the constitutionally contradictory player/avatar relationship. The player-here, Samantha-observes both the avatar and what the avatar observes. She manipulates the avatar (through verbal cues), while also imagining herself as being the avatar. Isabella performs effectively the cognitive, social, visceral, and fantasy functions of the avatar. But she is also sensitive to the internal life of the avatar, respecting Isabella's autonomy as a performer. "Does my body feel nice?" Samantha asks, using the first-person perspective to describe her performance with Isabella. In contrast, Theodore cannot (or will not) play the game. "Come on," Samantha enjoins him, "Get out of your head and kiss me." And still he refuses. Samantha changes tack, hoping a lighter touch might work: "Come on, Theodore, don't be such a worrier. Just play with me" (see Figure 6). Samantha has practice with avatars-and a willingness to imagine herself beyond her own body. But Theodore is incapable of joining in. He calls an end to the game, Isabella is humiliated, and Samantha begins to recognize the limits of her relationship with Theodore. Theo cannot do kinesthetic empathy. 


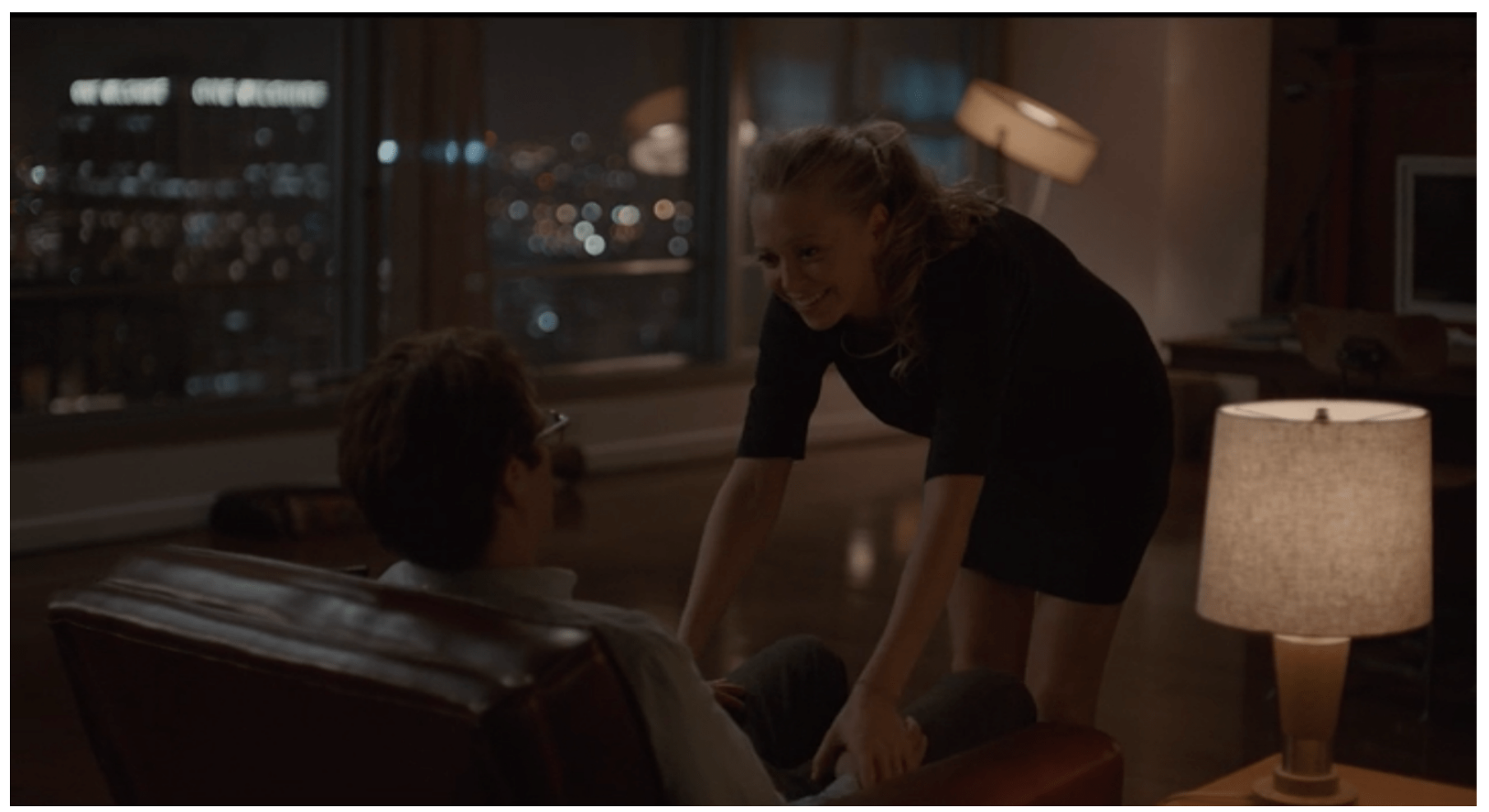

Figure 6. “Just play with me!” Samantha begs Theo, as she directs Isabella, a sex surrogate. (Screenshot created by author).

To reiterate, Her is not about videogames, but the way the movie incorporates them diegetically, figuratively, and procedurally enables director Jonze to find his way into the deep dynamics of love, enabling him to map, if you will, the procedural programming of the heart, the emotional software that enables us to empathize with each other, to help each other grow, to communicate, to have fun. But that programming can trap us as well, like a labyrinth. Her suggests that empathy is more than a matter of heart-it takes skill, too. And it demonstrates that the "videogame movie" can be much more than the adaptation of a recognized intellectual property or genre. While not centered on games, Her suggests that the capacity to play is an index of the capacity to love-to grow through love.

\section{1917 and the Emergence of Videogame Cinema}

Among 2019's most-honored films was 1917, Sam Mendes's harrowing tale of two British soldiers finding their way across the corpse-paved trenches and ruined villages of the Western Front to stop an attack that will cost 1600 British lives. However, as more than a few critics have noted, in terms of narrative, it is thin stuff. Mendes admits as much: "It's a fairly simple story: Two men have about eight hours to get from one part of the Western Front to another" (1917: Behind the Scenes Featurette 2019). The protagonists are thinly drawn, though vigorously performed by George MacKay and Dean-Charles Chapman. Mendes cops to that, too: "I wanted the audience ... to feel that they didn't know them" (1917: Behind the Scenes Featurette 2019). Ultimately, Schofield and Blake are types, the callow, stolid youth we have seen in dozens of war movies. And the obstacles they face are equally familiar: ruined cities, fallen bridges, snipers and explosions, fear and exhaustion, death and destruction, horror.

But character and plot are not what 1917 is about. 1917 is an immersive, intense, and categorically cinematic experience. And more than anything, it is a technical marvel, filmed and edited to suggest a single, unbroken take as we follow Schofield and Blake on every step of their journey. Thus, while it may be conventional in terms of the story it tells, it marks an unprecedented synthesis of the technical possibilities of digital cinematography, portable cameras, and the big-budget production capacities of contemporary action cinema. 
"One-shot" or "continuous-shot" films are relatively uncommon. We think perhaps of Alfred Hitchcock's Rope (1948) or Alejandro González Iñárritu's Birdman (2014), maybe Alexander Sokurov's Russian Ark (2002) or certain episodes of the television series Mr. Robot (2016) and The Haunting of Hill House (2018). Wikipedia lists around forty movies (and many more music videos). In contrast, long shots in otherwise conventional films are fairly common: the opening sequences of Touch of Evil (1958), Bonfire of the Vanities (1990), and Gravity (2013) are famous examples. There is the hallway fight in Oldboy (2003), the traffic jam in Jean-Luc Godard's Weekend (1967), the Dunkirk scene in Atonement (2007), the rescue of Kee and her child by Julian in Children of Men (2006). Regardless of how long the long shot may be, it draws attention to itself. It is virtuosic act of filmmaking, a cinematic flex.

It is a flex that is inseparable from the history of technological innovation. As Karl C. Ulrich puts it, "[T] he ever-evolving technology of motion picture production has continuously freed both the camera and the imagination of its operators to create even more sophisticated shot designs" (Ulrich 2016, p. 535). It is no accident that the number of films using long shots has increased with the development of camera-stabilizing inventions like Steadicam and, especially, small, portable digital cameras, which can go anywhere and film endlessly, unlike celluloid film cameras. This is the case with 1917, significant segments of which were filmed with the recently invented Trinity camera, which combines the mechanical stability of the Steadicam with an electronically controlled gimbal, enabling greater freedom of operator movement, more diverse camera angles, and significantly improved stability of frame (ARRI n.d.).

The history of long-shot cinema is part of the history of large-scale production management, too. A long shot requires extensive preparation, meticulous coordination of performers and crew, and more than a little good luck. And that is even if the movie takes place in a single location, with a small cast of characters, and few special effects. That is decidedly not the case with 1917, a sprawling epic with hundreds of extras, dozens of sets, and breathtaking special effects-almost all of it happening on location and outside. To get a taste of exactly how complex a task Mendes, Director of Cinematography Roger Deakins, Trinity camera operator Charlie Rizek, and Production Designer Dennis Gassner set for themselves, I recommend the making-of featurette, which I have already quoted and will quote from again. In sum, 1917 is a perfect example of the way new technologies and big-budget production design can reshape the way we experience movies.

But 1917 is not just a creature of camera technology and production design - it is a movie that reflects an evolution in the way we see and feel, or want to see and feel, movies. In an interview with Variety, Mendes says the idea for the film's look came to him while watching one of his children play videogames (Lang 2019). And not just any videogames, but third-person action-adventure games like Red Dead Redemption and Star Wars: Battlefront. "I find them remarkably mesmerizing, almost hypnotic. I just wanted to do something like that, but with real emotional stakes," Mendes says (qtd. in Lang 2019). Thus, as remarkable as the film's combination of cinematography and production may be, that is not what makes 1917 an unprecedented event in film history. 1917 marks an evolution in cinematic language, an evolution not so much inspired, but catalyzed by the videogame as a storytelling form and the way videogames have changed the way we comprehend visual narrative, part of a broader technocultural shift concerning the way "gaming affects our daily activities, including the lives of those who do not play games or participate in new media practices" (Boellstorf qtd. in Roig et al. 2009). In short, while 1917 is only one example of a "videogame movie," it is a singular harbinger of the emergence of something more subtle and significant: videogame cinema.

Not too many years ago, one could imagine that a veteran theatre and film director (and inexperienced game player) like Mendes would look at a videogame and be, if not confused, simply nonplussed. But that was not the case when he watched his child play. He saw something on that screen that made sense to him, that he understood opened a new possibility for storytelling, a new visual logic for connecting characters and audience. Mendes explains, "It felt like the best way to give you a sense of all this happening in real 
time. I wanted you to feel like you were there with the characters, breathing their every breath, walking in their footsteps. The best way to do that is not to cut away and give the audience a way out, as it were" (qtd. in Lang 2019). But if Mendes could see in the third-person videogame a way to make the experience immersive, it would appear that he did not see as clearly how that experience could be made emotionally moving. He failed to recognize how videogame players can be moved by the games they play, that there are real "emotional stakes" not simply to the visual logic of videogame storytelling but to the kinesthetic nature of play.

Mendes's remark about videogames sparked dozens of stories-and just as many uninformed takes about what 1917 borrows from the medium. What I will do here is identify precisely what Mendes and his team adapted from videogames, precisely how that borrowing shapes the visual logic of the film, and how that borrowing affects how we feel about young Schofield and Blake. This will require a fairly deep dive into what our eyes do when we play videogames - and how what we do with our eyes affects how our heart feels.

To begin with, let's understand exactly what kind of videogame inspired Mendes: third-person action-adventure games. In these, the player observes the action from just behind their avatar, the "camera" following close behind as we guide it through the game's spaces (see Figure 7). This form of videogame storytelling was first perfected by Epic Games's Gears of War (2006) and the third iteration of their Unreal Engine. The overthe-shoulder view and cover-based shooting mechanics of the Gears series might seem a relatively innocuous innovation, but the way it enabled players to move and shoot and explore; the way it enabled players to identify movement paths, targets, and places to hide; and (a seemingly minor but actually key feature) the way it enabled players to watch their avatar in action proved breathtakingly immersive. One might assume that the first-person view would be a much effective way to promote identification between player and avatar; after all, that perspective suggests a unity of embodied perspective. However, the third-person view proved powerfully engaging. The look and feel of Gears of War had an immediate and "huge knock-on effect," as Rob Leane puts it, most evidently in Naughty Dog's Uncharted: Drake's Fortune, in production at the time of Gears's release (qtd. in Leane 2019). Lucas Pope, hired by Naughty Dog in 2007 late in the game's development, explains, "Uncharted 1 was announced, and then Gears came out ... So, we changed everything, six months before release" (qtd. in Leane 2019).

But while Gears may have invented the visual logic of the third-person shooter, Uncharted perfected the storytelling — and that has made all the difference. Credit for that must go to Amy Hennig, director and writer of the first three Uncharted games, and one of the all-time great videogame storytellers. One of the hallmarks of Hennig's tenure with Naughty Dog was, as she puts it, a focus on "the integration of story and gameplay" that went beyond the almost exclusive focus on plot typical of most narrative-focused games at the time (qtd. in Marie 2010). As Hennig explains, action-focused games tend to focus on plot-on events, the discovery of new settings, the overcoming of physical obstacles, the elimination of antagonists, etc. They have generally paid far less attention on character and character development, and when that attention was paid, it tended to occur in cut scenes that removed the player from the action (Marie 2010).

In contrast, Hennig wanted the Uncharted series to "engage [players] viscerally and interactively, but ... also engage them on an emotional level" (qtd. in Marie 2010). This required a high-quality script, obviously, but also talented actors like Nolan North, Richard McGonagle, Emily Rose, Troy Baker, and Claudia Black, who could bring engaging, complex, evolving characters to life-and not just through their vocal performances. Not incidentally, these same actors performed in motion-capture, too, ensuring that the physicality of their performances would be in play and, to recall Gabriel Wei-Hao Chin again, provide a more fully articulated structure for enabling kinesthetic empathy. To recall, when we play in the third-person, we both manipulate and observe our avatar. Because the third-person view enables us to see what a character is feeling, storytelling-including 
character development-can happen on the fly and with a high level of performative physicality on the part of the avatar. Some of the best moments in the Uncharted series, for example, happen as characters talk to each other while we manipulate the avatar to solve spatial puzzles, moving from place to place, manipulating objects, and so on. And some of the best moments in character development happen as they move and climb and jump, their character expressed through their kinesthetic design. In sum, when we speak of the way the third-person action-adventure tells a story, we need to speak of the kinesthetic integration of character, action, and space and the particular ways that the player sees and feels while they play. In other words, the emotional power of the third-person perspective is not just its way of seeing, but its way of getting us to play.

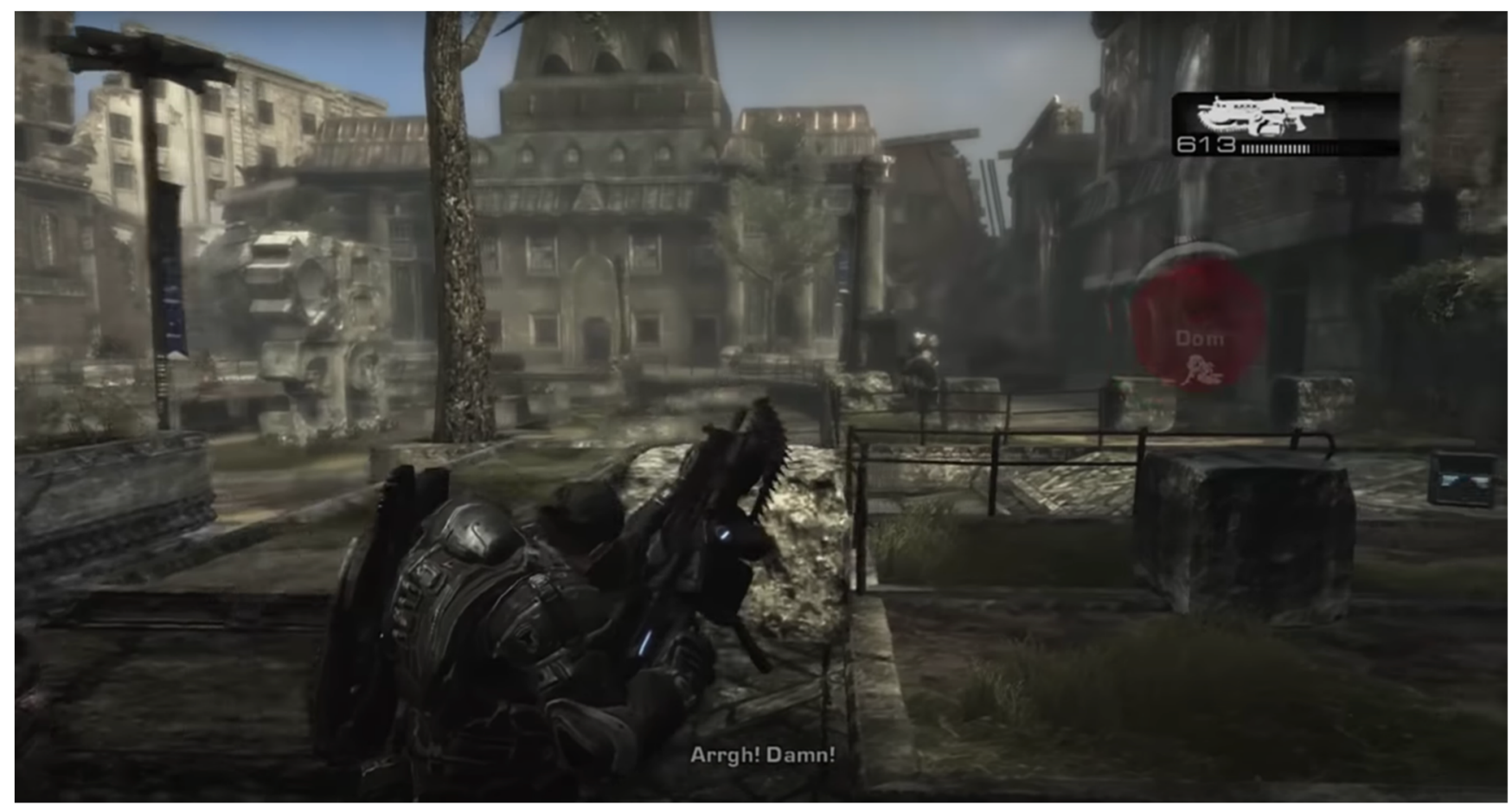

Figure 7. The third-person action-adventure videogame was pioneered by Gears of War (2006). (Screenshot created by author).

So, what does all this mean in terms of 1917? What does it tell us about how that movie tells its story? More importantly, what does it tell us about the direction cinematic storytelling may be going and how Mendes's film might signal a change in the way empathy is constructed in action-adventure films? To state the obvious, 1917 is not a videogame movie like the others I have described here. It portrays neither videogames nor videogame players. Rather, 1917 is a videogame movie because it adapts the visual procedures of the third-person action-adventure game. This is most apparent when the camera follows characters entering new, uncertain spaces, or struggling to reach an objective, or firing upon an enemy, or frantically seeking cover (see Figures 8-11).

But the mere fact of visual similarity is not a particularly fruitful point of comparison. Rather, what makes this film a "videogame movie" is the way Mendes and Deakins combine camera movement, mise-en- scène, the actors' performances, and the dramatic unfolding of the plot. The movement of character and camera into spaces of ambiguous threat and promise shapes a visual experience pioneered and perfected by the third-person shooter. And this is where we need to take a brief, but deep dive into the visual logic of videogames, the way the eye plays within that logic, and the particular forms of kinesthetic empathy that is promoted. 
The eye works differently when we play a videogame than it does when we watch a movie. A videogame player's visual attention continually shifts across different frames of reference, some of them diegetic, others not. For example, in this screen shot from Uncharted 2: Among Thieves (2009, see Figure 12), the player must look back and forth between the diegetic frame (Drake's involvement in a firefight with three bad guys) and the non-diegetic frame (the user interface which shows the kind of gun the player-character carries, the amount of ammunition left, and the fact that the player-character is injured, indicated by the red haze at the margin). The diegetic space is where the player's eye does most of its work-and many different sorts of work. In this second image from Uncharted 2 (see Figure 13), we see Drake being shot at by an enemy who is hidden inside a building (a fact we have deduced from the tracer path of a bullet it has fired at us). The player can see that Drake is safe from harm for the moment, having found reliable cover, but they also can see that they need to traverse the space between themselves and the enemy, which they must do without being hit by the enemy's fire and losing all their health, which would require them to respawn and try again from the start. To accomplish this, they must devise a solution to the challenge-possibly several solutions, in case the first (or second or third ... ) does not work out. This requires them to visually analyze and identify (1) potential paths across the space, (2) possible points of cover, (3) potential obstacles between them and the enemy (4) and potential targeting solutions with our current weapons (in this case, a pistol and a hand grenade). And all of this analytic work will need to be adjusted as Drake-and the camera that follows him-changes position.

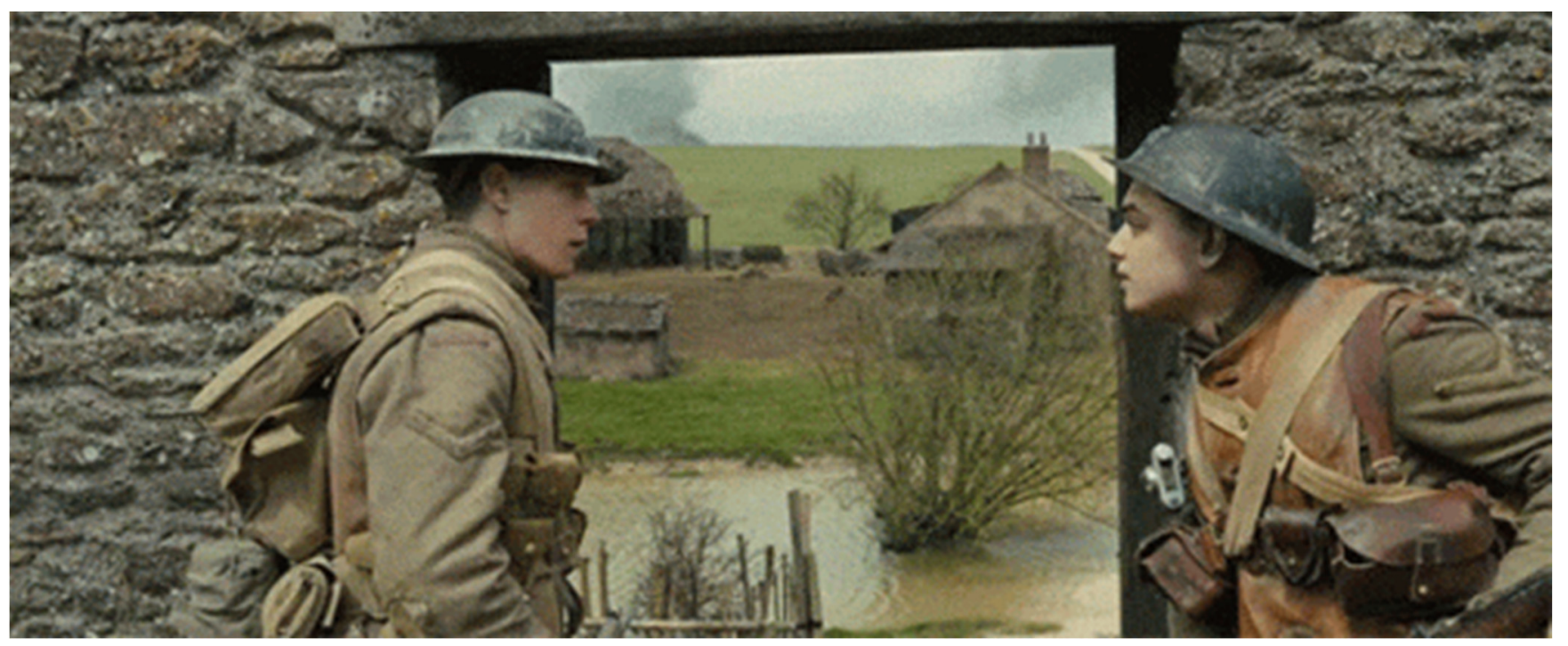

Figure 8. 1917 adapts the visual procedures of the third-person action-adventure game; for example, when characters are entering a space of uncertainty. (Screenshot created by author). 


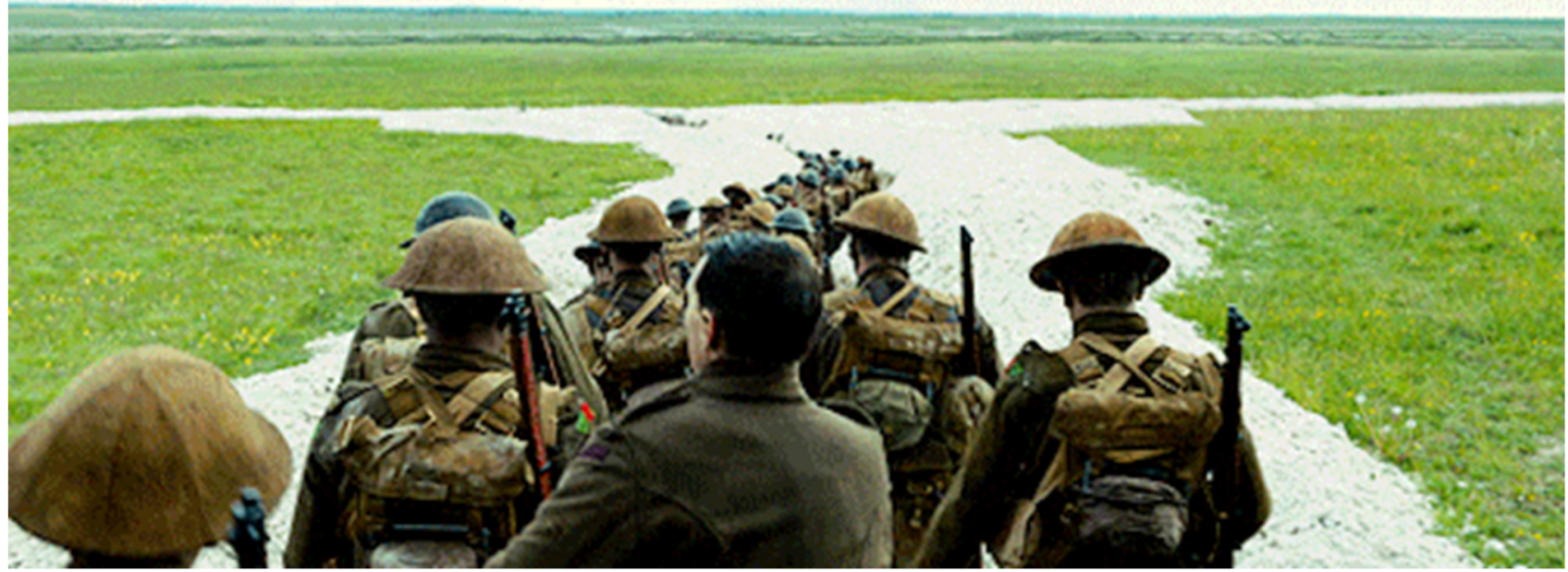

Figure 9. Or struggle to reach an objective. (Screenshot created by author).
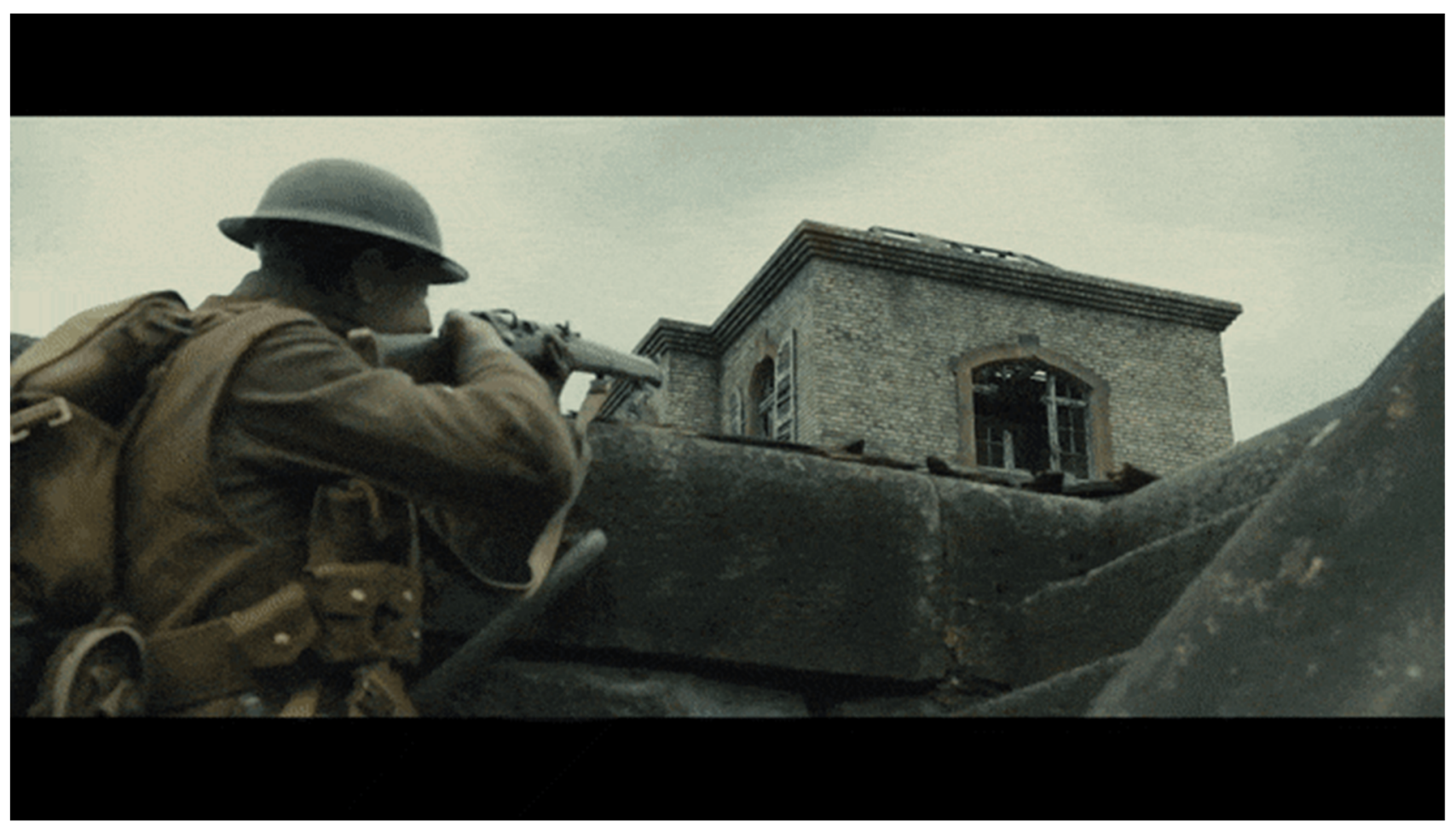

Figure 10. Or fire upon an enemy. (Screenshot created by author). 


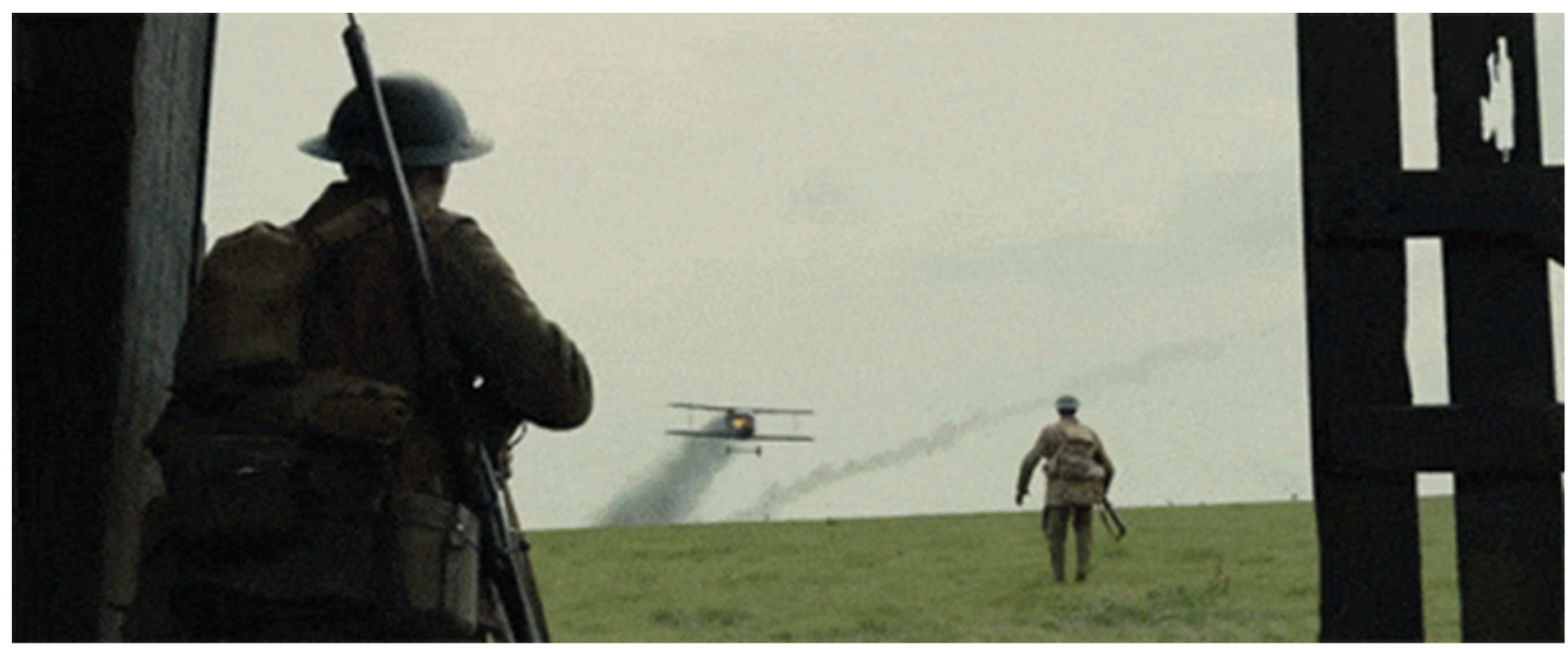

Figure 11. Or seek cover from an approaching enemy.

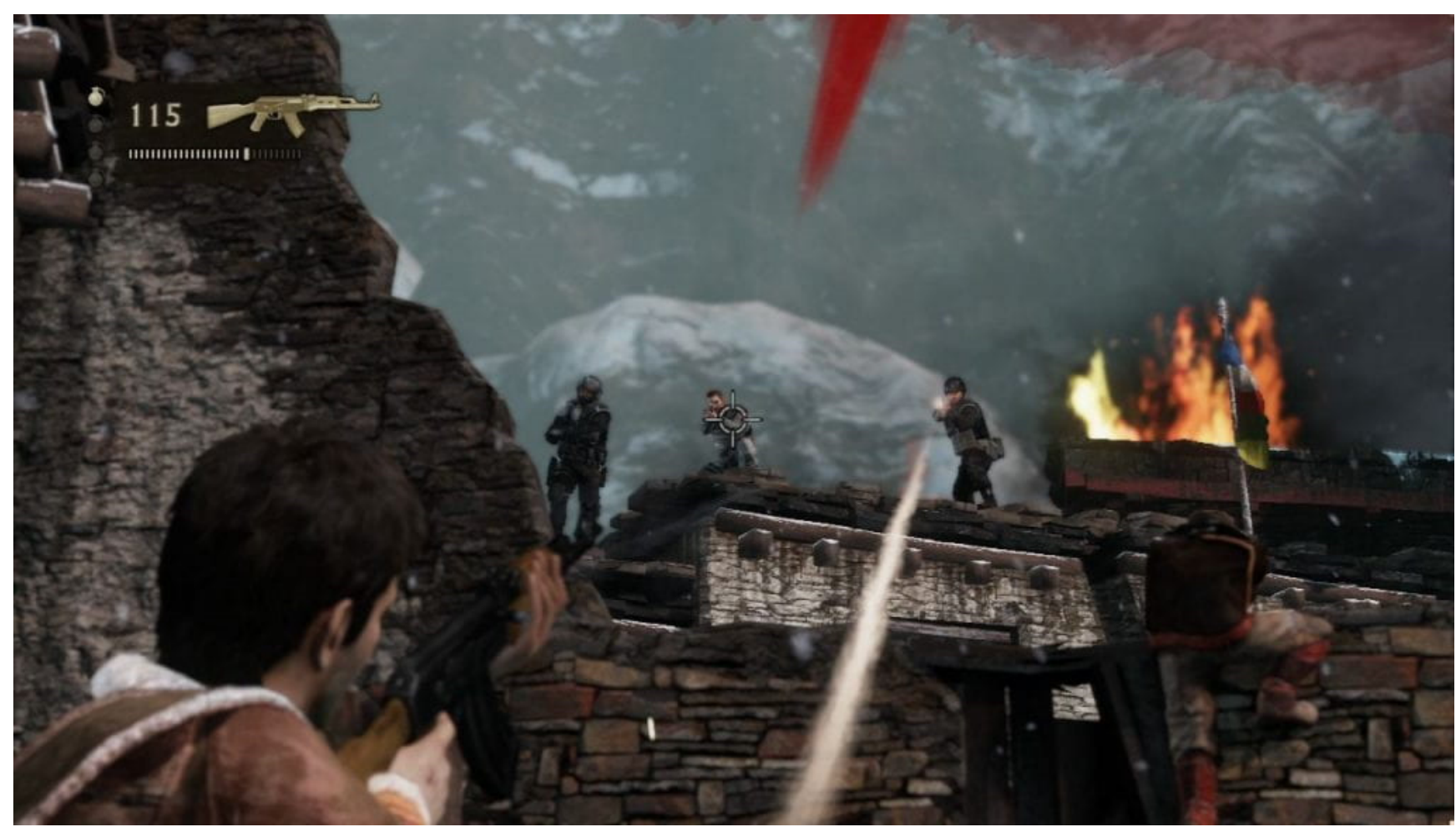

Figure 12. In third-person videogames like Uncharted 2, the player must look back and forth between the diegetic and non-diegetic frame. (Screenshot created by author). 


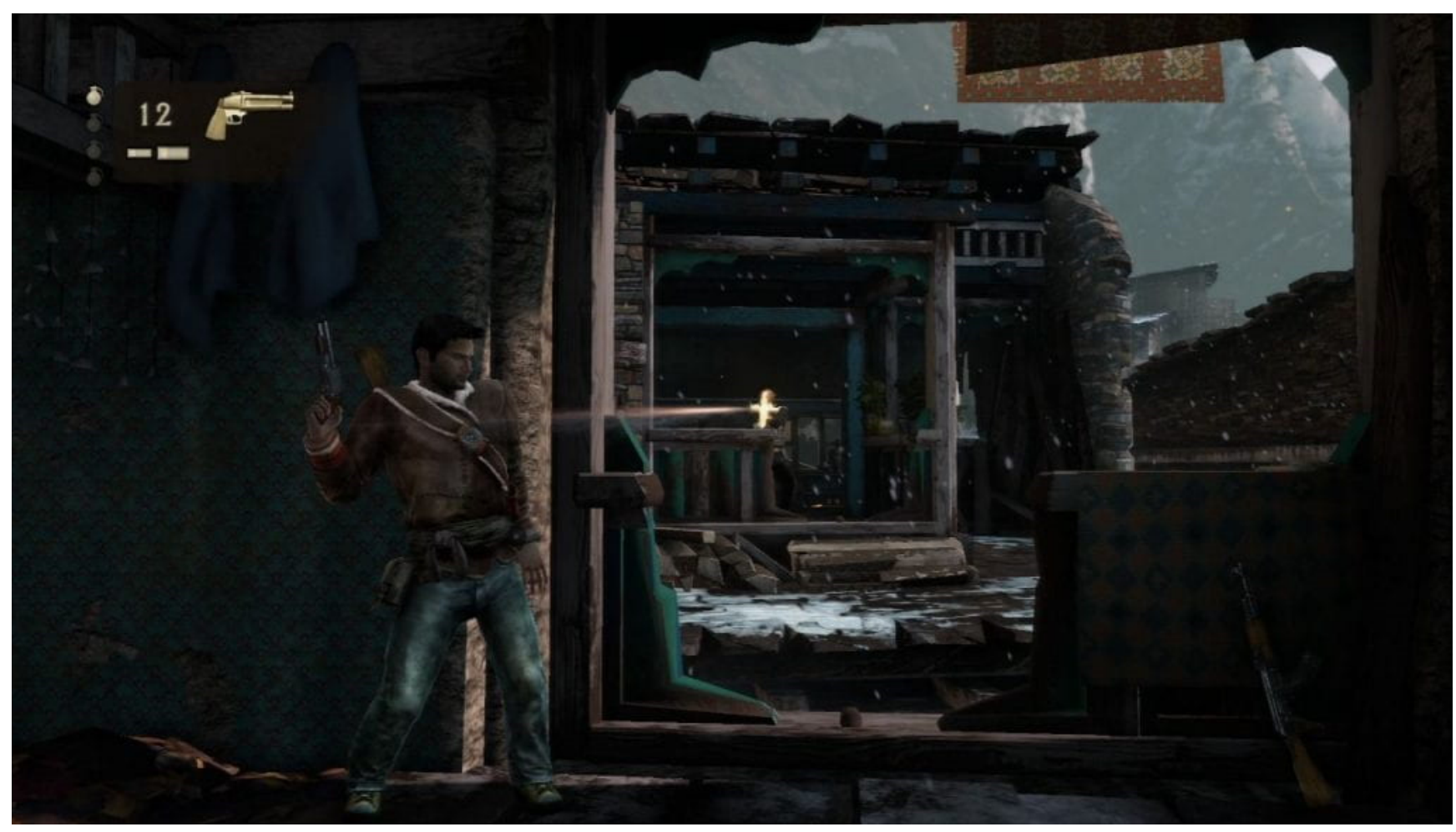

Figure 13. In third-person videogames like Uncharted 2, the player's eye must do many kinds of work simultaneously. (Screenshot created by author).

In addition to this essentially strategic-analytic labor, the eye must attempt to see into the future. As Barry Atkins explains, the player's gaze is always situated within a "specific temporality ... where the aesthetic is generated in a maelstrom of anticipation, speculation, and action" (Atkins 2006, p. 127). In this case, the player judges the current situation in the context of previous situations and in anticipation of the next. Drake and the player have been in this situation before-that is how we got here-and we know there are many more to come. Atkins further explains that this precognitive gaze is performative, in the sense that it is constructed by our participation within an unfolding and evolving situation, a situation affected by our connection with the avatar. As he puts it, "Videogames prioritize the participation of the player as he or she plays, and that player always apprehends the game as a matrix of future possibility" (Atkins 2006, p. 127). In this moment from Uncharted 2 , the player is not just devising a solution to the present problem-how to traverse a space that will expose the player-character to damage-but anticipating new challenges that may emerge during the attempt. They need to consider what will happen if they use their pistol or their hand grenade. They need to consider the additional enemies and obstacles that will likely emerge as they take their chance. That combination of contingency, anticipation, and surprise is one of the things that makes a videogame moment like this thrilling and fun. In videogames, the screen image "is full of rich possibilities of future action, pointing always off to the moment at which it will be replaced by another image then another" (Atkins 2006, p. 128). In sum, when playing third-person shooters, the eye is quite busy, engaged in multiple and simultaneous kinds of work. And it is busy in a fashion that is distinct from a first-person shooter. That distinctiveness is, as Katherine Isbister notes, the subject of "ongoing debate in the game design community," reflecting the fact that "[s]ome players report that a first-person perspective helps them immerse themselves completely in their alternative identity, while others find the third-person view more compelling, as it "helps continually remind players who they are supposed to be in the game" (Isbister 2016, p. 14). The opinions of players notwithstanding, it is evident that 
point of view is a key mediator of choice, flow, and social emotions in games, unifying the cognitive, social, visceral, and fantasy dimensions of the avatar (Isbister 2016, p. 11).

This is a matter of both narrative and technical design. In a fascinating study of player eye-movement patterns in videogames, Magy Seif-El-Nasr and Su Yan demonstrate that, first, the gaze in videogames is typically task-dependent: our eyes need to identify and achieve objectives, usually in situations where the failure to do so will result in the need to retry. Once this more utilitarian analysis is complete, the eye will start to attend to what might broadly be deemed "aesthetic matters," ascertaining the features of the environment that communicate narrative content, atmosphere, and so on. In other words, when we enter a game environment, we look first to what Jorge Muñoz et al. call the "useful grid", then to the narrative (Muñoz et al. 2011, p. 48). In this respect, the gaze performs similarly in most genres of videogames and is a pillar of the kinesthetic-empathetic relationship I described earlier in my analysis of Her. As David Owen (2017) explains, the manipulation of controller and the perception of an extended body in game space produces a proprioceptive illusion of inhabiting that body both physically and emotionally. The videogame player is thus able to "empathize with the active agent in the narrative (the game character) but also see herself as the active agent (performing actions through the character as her avatar, even when not visible as in first-person shooters" (Muñoz et al. 2011, p. 23). This generates a "feeling of agency" and an "empathic connection to not only the player's avatar, but also, potentially, other non-player characters ... " (Muñoz et al. 2011, p. 23).

However, the visual logic of third-person games shapes the player's gaze in three distinct ways that impact the feeling of agency and the nature of the empathic connection. First, the eye continually shifts between avatar and environment, the result of the need to simultaneously position the avatar and identify and accomplish objectives (El-Nasr and Yan 2006, pp. 4-5). Second, unlike first-person games (in which the gaze of the player and the avatar coincide), the gaze of third-person players continually shifts between the perspective provided by the camera and the perspective the player imagines their avatar to have. This process is further complicated if the game enables the player to voluntarily shift camera mode; for example, to occupy a position over the shoulder of the avatar to enable more accurate targeting, which temporarily shifts the ratio between player-gaze and character-gaze. In short, the eye in the third-person shooter is an unusually active eye, as shown in this diagram of eye movement patterns in Halo II (2004, a first-person game) and Blood Omen: Legacy of Kain II (2002, a third-person game) (see Figure 14). As we can see, the player's eye in the third-person game (indicated by the pink lines) is scanning a significantly greater part of the visual field than the player's eye in the first-person game (indicated by the blue lines), due, as El-Nasr and Yan explain, to the disconnect between player eye and character eye (El-Nasr and Yan 2006, p. 6).

Which leads to the third, and I think crucial, difference between how we see in the third person and how we see in the first. When we play the former, we are continually reminded of the difference between ourselves and our avatar. As we play, we simultaneously observe and identify with the protagonist. In other words, as we attempt to see as the avatar-to see as a player-character-we must adjust our seeing to a character performing within the narrative space. In games where the protagonists grow and change, the player's way of seeing must also grow and change, adjusting not only to the evolving technical capacities of the avatar (who may be gaining new powers or new applications of old powers, changing the way they look and move) but also to their evolving persona. 


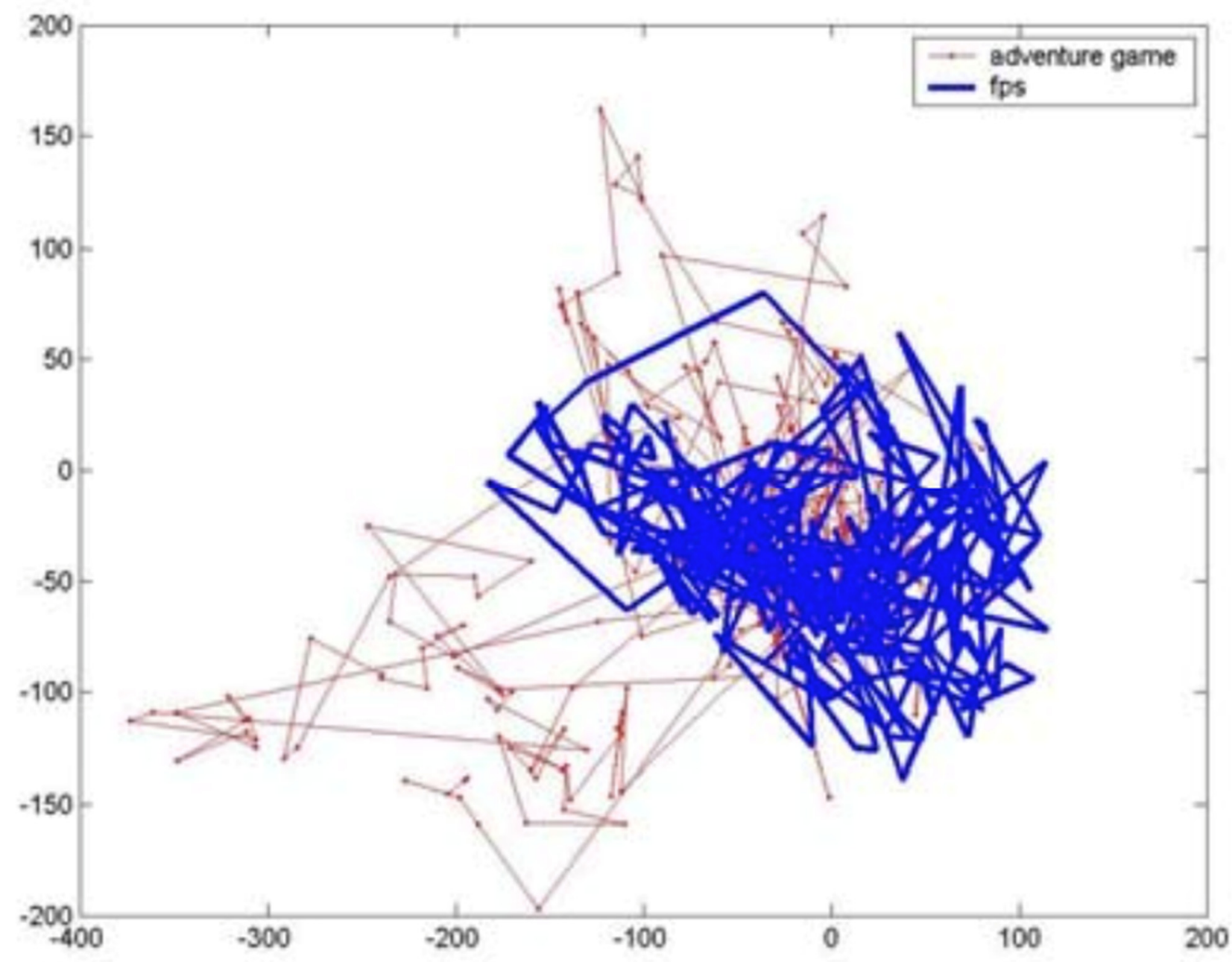

Figure 14. Diagram of player eye movement in first-person (blue lines) and third-person (red lines) games. Used with permission of Magy Seif el-Nasr.

We both see the character and see as the character.

Though it might seem paradoxical, it is precisely because we are never allowed to experience seamless and consistent identity between our own seeing and the avatar's seeing that we are able to empathize all the more strongly with the avatar. To recall Amy Hennig, there is an empathy constructed by the integration of play and plot, and there is an empathy created by the integration of play and character. Narrative matters when it comes to empathy. As David Owen sums it up, when "willing suspension of disbelief, a compelling reason to engage, and achieving the condition of flow" are achieved, a deep sense of empathic connection can be achieved (Owen 2017, p. 47).

So, how does the spatial and temporal character of the third-person action-adventure gaze translate from a videogame to a movie screen-specifically, to the visual language created by Mendes, Deakins, and Trinity camera operator Charlie Rizek. First, unlike the roving camera in Russian Ark, the camera in 1917 is not a character; it does not express a particular point of view. Unlike, say, the long shot in Soy Cuba (1964) that moves from a rooftop beauty pageant to a woman in a bikini diving into a swimming pool, casting harsh light on the decadent lifestyle of bourgeois Cubans and tourists, the camera in 1917 does not communicate a specific thematic or critical perspective on what it shows. In fact, quite the opposite. Deakins explains that he did not want the camera to draw any attention to itself: "It's not that kind of film," he tells us. "You just wanted it to disappear in the image, and for the most part, I think that's quite successful" ("1917 Behind the Scenes Featurette"). In other words, the camera in 1917 is designed to function as a neutral eye, 
providing the viewer the opportunity to engage in the kind of multi-faceted seeing that we associate with videogames, particularly those told through the third-person perspective. It's intriguing to think about what kinds of social and historical forces are driving this kind of innovation. One might speculate that the development of cameras like the Trinity, which combines mechanical and electronic stabilization, is being driven by the kinds of fluid camera movements that can be achieved in videogames, which do not require a human operator lugging a fifty-pound harness. Certainly, that was the case with 1917, which was directly inspired by the fluid, non-human capacities of the videogame camera. This is a fascinating integration into cinema of the understandings, rules, and motivations of the videogame medium, to recall Roig et al. 2009, once more (p. 93). And it signals an unprecedented moment in the evolution of cinema.

Second, like the third-person action-adventure videogame, the actions of the characters are meticulously integrated with dramatic space-indeed, were invented concurrently. Mendes explains, "We had to measure every step of the journey" ("1917 Behind the Scenes Featurette"). Dean-Charles Chapman describes early rehearsals with Mendes and Deakins on an "open field that was pretty much nothing there": "We had the script in our hand and we literally just walked and talked every single scene to see how long it took us to get from A to B" ("1917 Behind the Scenes Featurette"). Mendes elaborates, "The scene has to be the exact length of the land, and the land cannot be longer than the scene, and the scene cannot be longer than the land, and so you have to rehearse every line of dialogue on location. And that's where it overlaps with doing theatre, because the world has to be crafted around the rhythm of the script" ("1917 Behind the Scenes Featurette"). Michael Lerman, co-producer and first assistant director, describes the process as alien to the usual way of doing things: "You almost have to change the way you think about how we view movies ... and how we make movies as a filmmaker" ("1917 Behind the Scenes Featurette").

Finally, suspense is generated through the limited perspective of the protagonist. In a conventional film, suspense can be created by cutting across the spaces of a scene. A tripwire trap in an underground bunker might be shown first, then the characters entering the bunker, then a rat moving towards the tripwire, then the characters' approach, etc. Or the camera might rove in a continual shot in and around an abandoned farm, perhaps capturing the characters approaching from distance, perhaps suggesting the gaze of a hidden enemy. But in 1917, suspense is created entirely from the perspective of Blake and Schofield-or, more precisely, from just behind them.

So, how does this all come together? Let's take a closer look at a scene from the film's second half. Schofield has moved into a town devastated by artillery, occupied by Germans, and under attack by the British. It is night; light is provided by the flickering flames of burning buildings and the harsh, shifting glare of flares. Attempting to evade enemy fire and find allies, Schofield moves into a plaza, the camera close behind. A church is burning, casting both the protagonist and the fountain to the left in silhouette and obscuring everything in amber smoke. From out of the haze, we see another person emerge, clearly a soldier, but his alliance uncertain, as he is too far away to identify and his gun is held away (see Figure 15). This suddenly changes. He points his gun at Schofield (see Figure 16) and fires, evident from the muzzle flash, which causes Schofield to scramble away (see Figure 17).

For players of third-person-perspective videogame shooters, this situation is entirely familiar: a space full of unclear sightlines, a moving figure that may or may not be an enemy, a sudden realization of danger. The suspense of moments like these, whether in a videogame or a third-person movie like 1917, is generated by the appearance of a figure whose identity is unclear and potentially threatening, requiring our eyes to engage simultaneously in the kinds of analytic, aesthetic, and empathetic work I described earlier. The thrill of moments like these is generated by the close, but imperfect and shifting alignment of the viewer's and the character's gaze. The result is a moment of dramatic alignment of gaze, storytelling, and empathy. 


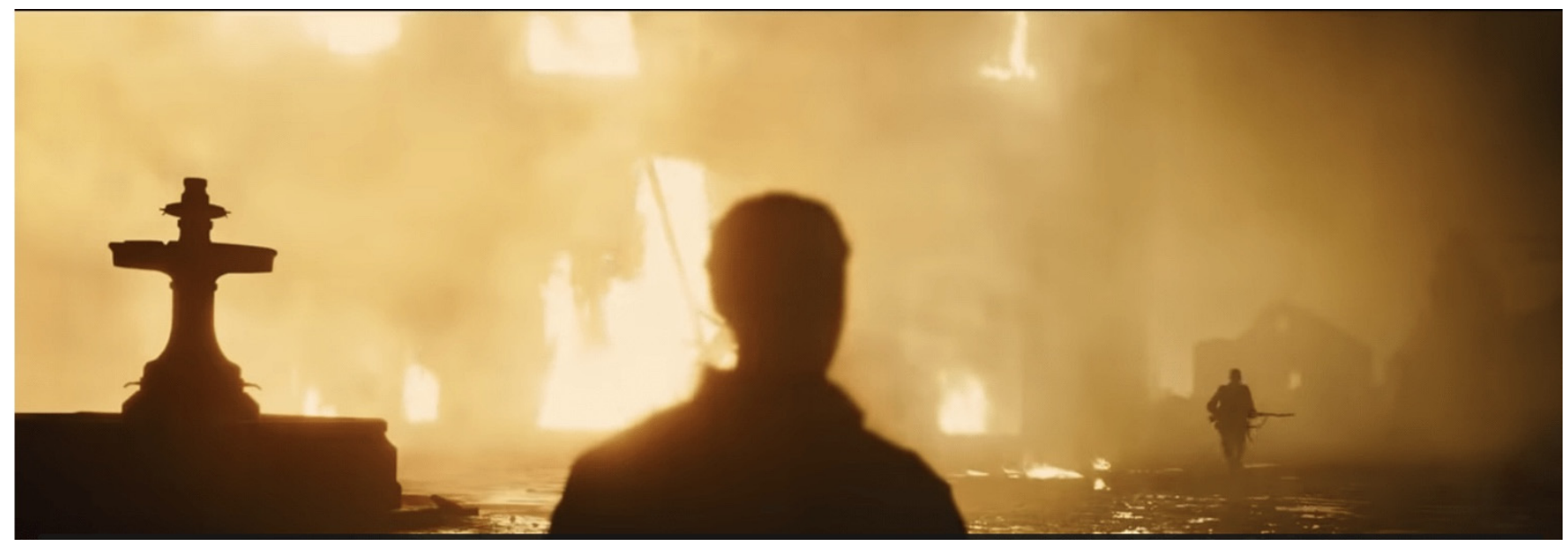

Figure 15. From out of the haze, we see another person emerge. (Screenshot created by author).

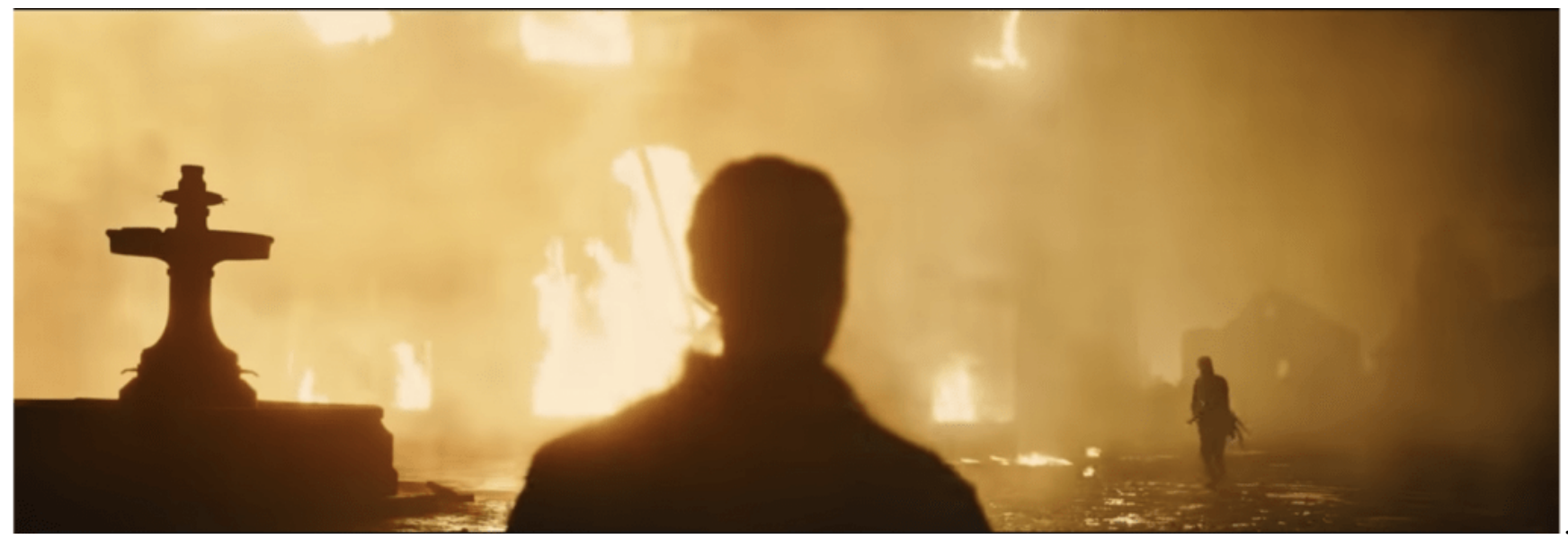

Figure 16. They raise their weapon, their intentions unclear. (Screenshot created by author).

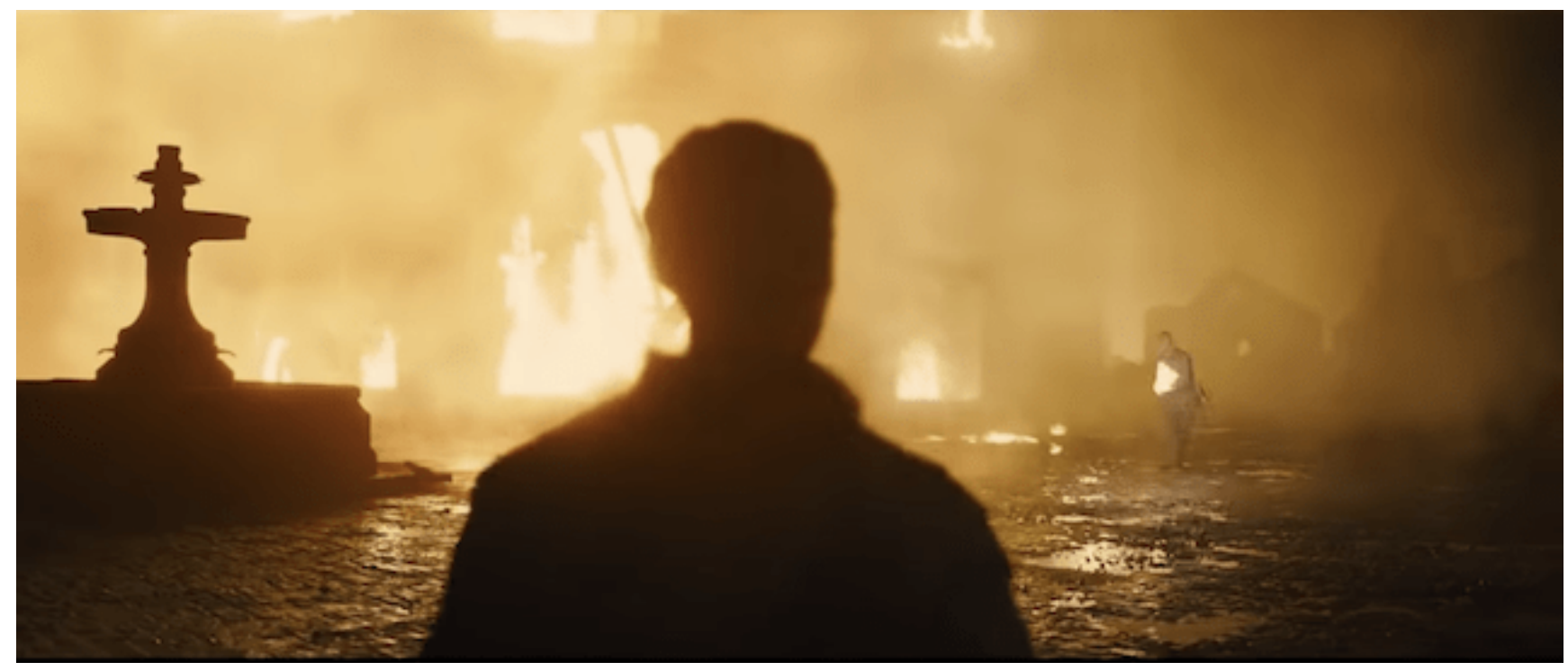

Figure 17. The muzzle of their gun flashes. Schofield is being attacked! (Screenshot created by author). 
But technical achievement does not necessarily equate with artistic accomplishment. I share the opinion of many critics that it is difficult to feel much for the characters in 1917. Peter Sobczynski (2019) sums up this broadly held opinion when he writes, "And yet, for all of its technical expertise, little of it helps viewers to care about the characters or what might happen to them." The hamstrung empathy of the film is best illustrated by the moment at its conclusion when Schofield opens the small folio he has been carrying inside his tunic. We have seen that portfolio before, but neither Schofield nor the viewer were allowed to see its contents before this moment. And, frankly, what is inside is no less unsurprising than most of the storyline of 1917: a photograph of someone he loves. But that folio and the tepid response it evokes (what else would it be?) is less a problem of script than a challenge that videogame cinema will pose to those who attempt it in the future.

What is missing is precisely what Mendes found lacking in those inspirational videogames he watched his kids play: emotional stakes. But here's the irony: those stakes are not missing in games. Mendes just could not feel them, because the emotional stakes generated by videogames are not just a matter of seeing. Videogames are not movies. One cannot see the emotional stakes, one must play those emotional stakes. The empathy generated by videogames is generated as much by our hands and analyzed by our eyes as they are by what the characters say or emote.

Yes, cinematic empathy in action can create powerful forms of identification between viewer and protagonist-the kind of identification that we associate with jump scares, vertigo-inducing sightlines, and narrow escapes. Mendes and Deakins achieve precisely that identification in the long-shot opening sequence of Spectre (2015), but their success in that endeavor was due at least in part to our familiarity with the character of James Bond and to Daniel Craig's performance. As Hennig and other great videogame creators show us (i.e., Cory Barlog, Hideo Kojima, Matt Sophos, Robin Hunicke, Shigeru Miyamoto, Marcin Blancha, Paul Dini), achieving empathy in action is not just a matter of integrating plot, action, and cinematography. Consider what Steven Spielberg, Lawrence Kasdan, and Harrison Ford achieve in Raiders of the Lost Ark (1981). Indiana Jones does not speak for the first four minutes of the film and says very little for the next eight. But we get to know Indy intimately through what he does and how he moves: the sudden shift from satisfaction to terror as a vine slips through his fingers, the abnormal care he shows for his fedora, the clouds of dust he sheds as he runs across an open field. Empathy is achieved between viewer and character kinesthetically.

It is curious that actors George MacKay and Dean-Charles Chapman, having developed their characters from virtually the first day of pre-production, did not devise the kinds of subtle physical quirks that would enable the viewer to achieve a richer quality of kinesthetic empathy with their characters. Perhaps their inexperience as action performers is to blame? Perhaps it is due to their first performances on the untouched fields and farms of Salisbury being reified into the clockwork design of the production, denying them the opportunity to further develop their character's embodied personas and forcing them to perform not as people responding viscerally and spontaneously to the moment, but as actors hitting their marks? Perhaps videogame cinema demands a different kind of physicality from its performers, perhaps a style we associate with silent film stars like Charlie Chaplin, Mary Pickford, Douglas Fairbanks, Greta Garbo, and Harold Lloyd. Or with action performers like Bruce Lee, Zoë Bell, Jackie Chan, Dwayne Johnson, Michelle Rodriguez, Uma Thurman, or Daniel Craig. Or with videogame performers like Nolan North, Troy Baker, Laura Bailey, Emily Rose, and Claudia Black. Or with brilliant motion-capture actors like Andy Serkis.

As Michael Chemers and I argue in Systemic Dramaturgy: A Handbook for the Digital Age (Chemers and Sell 2022), every technological advancement in the performing arts provides new ways to delight the eye, inspire the imagination, and move the heart. But every technological advancement inevitably, sometimes permanently, alters the calculus of eye, imagination, and heart. This is perhaps nowhere more true than videogames, which have generated remarkable ways to engage their audiences-and, as the events of Gamergate 
demonstrated, been instrumental in the development of new ways to feel and communicate hatred, new ways to imagine and wreak violence. If 1917 signals the emergence of a true videogame cinema, then it also signals the emergence of a new set of challenges for those who wish to make audiences care.

\section{From What We Know to What We Can Imagine, from Tropes to Theory}

What is a videogame movie? As I hope I have demonstrated, this is a question that benefits from a broader perspective on the films that might "count" as such and from a more rigorous understanding of their generic character. While movies that are centered on videogames, videogame players, and videogame culture have much to teach us about the evolving technoculture developing around videogames, so do the movies that do not center their focus in that fashion. In fact, those films where videogames appear incidentally may teach us far more about the way videogames are becoming part of everyday life and reorganizing the way we see and hear and feel the world around us. However, in order for us to broaden our perspective and achieve a more rigorous understanding of the genre, we need to recognize the variety of ways that adaptation can function and the variety of films in which adaptation occurs. To that end, I have designated six tropes whose presence in a film identifies it as a videogame movie and a text that may hold potential for further analysis:

Fictive adaptation

Supplementary adaptation

Diegetic representation

Figurative representation

Intertextual reference

Procedural adaptation

These tropes, derived from the piecemeal archive of films generally recognized by scholars as "videogame movies" and from those that I have identified, provide concrete criteria for designating texts that may deserve our attention.

For if it is guaranteed that videogames are going to change as new technologies emerge and new player tastes develop, it is also a certainty that other technologies and other player communities will be discovered, some of them in play right now, yet others in the past, perhaps the quite distant, pre-digital past. And if we accept that notion, then it is just as certain that the formal structures and thematic concerns of videogame movies will change as well. Indeed, a film like 1917 suggests that the adaptive relationship between videogames and movies has reached a point where the cinematic gaze is being reconstructed under the pressure and pleasures of the videogame. In sum, before we can tell the history of the videogame movie, we need to construct the archive, and I am quite certain that archive has more than a few surprises in store.

Funding: This research received no external funding.

Institutional Review Board Statement: Not applicable.

Informed Consent Statement: Not applicable.

Conflicts of Interest: The author declares no conflict of interest.

\section{References}

1917. 2019. Directed by Sam Mendes. Cinematography by Roger Deakins. Camera Operation by Charlie Rizek. Performances by Dean-Charles Chapman and George MacKay. Glendale: Dreamworks.

1917: Behind the Scenes Featurette. 2019. Universal Pictures. Available online: https://www.universalpictures.com/movies/1917 (accessed on 9 February 2020).

Abrams, Bryan. 2013. Production Designer K.K. Barrett on Creating Her's Beautiful Future. The Credits, December 10. Available online: https:/ / www.motionpictures.org/2013/12/production-designer-k-k-barrett-on-creating-hers-beautiful-future/ (accessed on 19 March 2020).

Anthropy, Anna. 2012. Rise of the Videogame Zinesters. New York: Seven Stories Press. 
ARRI. n.d. Trinity: First Hybrid Camera Stabilizer. Available online: https://www.arri.com/en/camera-systems/camera-stabilizersystems /trinity\#: \{\}:text=TRINITY\%20is\%20the\%20first\%20hybrid,bit\%20ARM\%2Dbased\%20gimbal\%20technology.\&text= Additional\%20stabilization\%20in\%20the \%20roll\%20axis\%20permits \%20the \%20use \%20of\%20telephoto \%20lenses (accessed on 4 January 2021).

Assunção, Carina. 2016. "No Girls on the Internet": The Experience of Female Gamers in the Masculine Space of Violent Gaming. Press Start 3: 46-65.

Atkins, Barry. 2006. What Are We Really Looking At? The Future-Orientation of Video Game Play. Games and Culture 1: 127-40. [CrossRef]

Bogost, Ian. 2008. The Rhetoric of Video Games. In The Ecology of Games: Connecting Youth, Games, and Learning. Edited by Katie Salen, The John D. and Catherine T. MacArthur Foundation Series on Digital Media and Learning; Cambridge: The MIT Press.

Boluk, Stephanie, and Patrick LeMieux. 2017. Metagaming: Playing, Competing, Spectating, Cheating, Trading, Making, and Breaking Videogames. Minneapolis: University of Minnesota Press.

Chemers, Michael M., and Mike Sell. 2022. Systemic Dramaturgy: A Handbook for the Digital Age. Carbondale: Southern Illinois University Press.

Chin, Gabriel Patrick Wei-Hao. 2017. Observed Bodies and Tool Selves: Kinaesthetic Empathy and the Videogame Avatar. Digital Creativity 28: 206-23. [CrossRef]

Clark, Naomi, and Merritt Kopas. 2015. Queering Human-Game Relations: Exploring Queer Mechanics and Play. First Person Scholar, February 15. Available online: http:/ / www.firstpersonscholar.com/queering-human-game-relations/ (accessed on 23 June 2020).

Dixon, Steve. 2007. Digital Performance: A History of New Media in Theater, Dance, Performance Art, and Installation. Cambridge: The MIT Press.

El-Nasr, Magy Seif, and Su Yan. 2006. Visual Attention in 3D Video Games. In Paper presented at ACE '06: Proceedings of the 2006 ACM SIGCHI International Conference on Advances in Computer Entertainment Technology, Los Angeles, CA, USA, June 14-16.

Franklin, Seb. 2015. Control: Digitality as Cultural Logic. Cambridge: MIT Press.

Her. 2013. Directed by Spike Jonze. Production Designer K. K. Barrett. Performances by Portia Doubleday, Scarlett Johansson and Joaquin Phoenix. Los Angeles: Annapurna Pictures.

Hills, Matt. 2002. Fan Cultures. London: Routledge.

Howard, Jeff. 2008. Quests: Design, Theory, and History in Games and Narratives. Wellesley: A K Peters, Ltd.

Isbister, Katherine. 2016. How Games Move Us: Emotion by Design. Cambridge: The MIT Press.

Jenkins, Henry. 2006. Convergence Culture: Where Old and New Media Collide. New York: NYU Press.

Johnson, Mark R. 2019. Deep Play and Dark Play in Contemporary Cinema. New Review of Film and Television Studies 17: 405-22. [CrossRef]

Kallay, Jasmina. 2013. Gaming Film: How Games Are Reshaping Contemporary Cinema. London: Palgrave Macmillan.

Karhulahti, Veli-Matti. 2015. Defining the Videogame. Game Studies. p. 15. Available online: http://gamestudies.org/1502/articles/ karhulahti (accessed on 23 May 2020).

Keane, Steve. 2002. From Hardware to Fleshware: Plugging into David Cronenberg's eXistenZ. In ScreenPlay: Cinema/Videogames/Interfaces. Edited by Geoff King and Tanya Krzywinska. New York: Wallflower Press.

King, Geoff, and Tanya Krzywinska, eds. 2002. ScreenPlay: Cinema/Videogames/Interfaces. New York: Wallflower Press.

Lang, Brent. 2019. How Sam Mendes and Roger Deakins Pulled off the One-Shot War Epic 1917. Variety, December 5. Available online: https:/ / variety.com/2019/film/news/sam-mendes-roger-deakins-1917-1203425116/ (accessed on 8 March 2020).

Leane, Rob. 2019. How Gears of War inspired Uncharted. Den of Geek, January 22. Available online: https:/ /www.denofgeek.com/ games/how-gears-of-war-inspired-uncharted/ (accessed on 12 May 2020).

MacTavish, Andrew. 2002. Technological Pleasure: The Performance and Narrative of Technology in Half-Life and Other HighTech Computer Games. In ScreenPlay: Cinema/Videogames/Interfaces. Edited by Geoff King and Tanya Krzywinska. New York: Wallflower Press.

Manovich, Lev. 2001. The Language of New Media. Cambridge: The MIT Press.

Marie, Meagan. 2010. Storytellers of the Decade: Amy Hennig. Game Informer, December 2. Available online: https://www. gameinformer.com/b/features/archive/2010/12/02/storytellers-of-the-decade\%3A-amy-henning-interview.aspx (accessed on 21 May 2020).

Muñoz, Jorge, Georgios N. Yannakakis, Fiona Mulvey, Dan Witzner Hansen, German Gutierrez, and Araceli Sanchis. 2011. Towards Gaze-Controlled Platform Games. Paper presented at 2011 IEEE Conference on Computational Intelligence and Games (CIG'11), Seoul, Korea, August 31-September 3; pp. 47-54.

Owen, David. 2017. Player and Avatar: The Affective Potential of Videogames. Jefferson: McFarland \& Company, Inc.

Papazian, Gretchen, and Joseph Michael Sommers, eds. 2013. Game on, Hollywood! Essays on the Intersection of Video Games and Cinema. Jefferson: McFarland \& Company.

Penix-Tadsen, Philip. 2016. Cultural Code: Video Games and Latin America. Cambridge: The MIT Press.

Reynolds, Dee, and Matthew Reason, eds. 2012. Kinesthetic Empathy in Creative and Cultural Practices. Chicago: University of Chicago Press. 
Roig, Antoni, Gemma San Cornelio, Elisendra Ardèvol, Pau Alsina, and Ruth Pàges. 2009. Videogame as Media Practice: An Exploration of the Intersections between Play and Audiovisual Culture. Convergence: The International Journal of Research into New Media Technologies 15: 89-103. [CrossRef]

Ryan, Marie-Laure, and Jan-Noël Thon, eds. 2014. Storyworlds across Media: Toward a Media-Conscious Narratology. Lincoln: University of Nebraska Press.

Ryan, Marie-Laure, ed. 2004. Narrative across Media: The Languages of Storytelling. Lincoln: University of Nebraska Press.

Salen, Katie, and Eric Zimmerman. 2003. Rules of Play: Game Design Fundamentals. Cambridge: The MIT Press.

Shaw, Adrienne. 2014. Gaming at the Edge: Sexuality and Gender at the Margins of Gamer Culture. Minneapolis: University of Minnesota Press.

Sicart, Miguel. 2017. Queering the Controller. Analog Game Studies. p. 4. Available online: http://analoggamestudies.org/volume-ivissue-iv / (accessed on 9 June 2020).

Silverstone, Roger. 1999. Why Study the Media? London: SAGE Publications.

Sobczynski, Peter. 2019. Review: 1917. RogerEbert.com, December 25. Available online: https://www.rogerebert.com/reviews/1917 -movie-review-2019 (accessed on 3 January 2021).

Sullivan, Anne, Michael Mateas, and Noah Wardrip-Fruin. 2009. QuestBrowser: Making Quests Playable with Computer-Assisted Design. UC Irvine: Digital Arts and Culture. Available online: https://escholarship.org/uc/item/2tk0h882 (accessed on 29 January 2021).

Sullivan, Anne. 2009. Gender-Inclusive Quest Design in Massively Multiplayer Online Role-Playing Games. Paper presented at the 4th International Conference on Foundations of Digital Games, FDG 2009, Orlando, FL, USA, April 26-30.

Ulrich, Karl C. 2016. A Short Look at the Long Take: The Art and Craft of Cinematic Camera Movement. ASBBS Proceedings 23: 535-39.

Uncharted 2: Among Thieves. 2009. Uncharted 2: Among Thieves (Game of the Year Edition). Playstation 3 version. Santa Monica: Naughty Dog.

Wardrip-Fruin, Noah. 2005. Playable Media and Textual Instruments. Dichtung Digital. Available online: http://www.dichtung-digital. de/2005/1/Wardrip-Fruin/index.htm (accessed on 29 January 2021).

Wolf, Werner. 2006. Frames, Framings, and Framing Borders on Literature and Other Media. In Framing Borders in Literature and Other Media. Edited by Werner Wolf and Walter Bernhart. New York: Editions Rodopi.

Yee, Nick, and Jeremy Bailenson. 2007. The Proteus Effect: The Effect of Transformed Self-Representation of Behavior. Human Communication Research 33: 271-90. [CrossRef]

Yee, Nick. 2006. The Demographics, Motivations and Derived Experiences of Users of Massively-Multiuser Online Graphical Environments. PRESENCE: Teleoperators and Virtual Environments 15: 309-29. [CrossRef] 